\title{
Grape Pruning Material Improves Root Development and Soil Microecology in 'Shine Muscat' Grape Soils
}

\author{
Hong Su, He Zhang, Chaoxia Wang, Jianquan Huang, Jiayin Shang, \\ Na Zhang, Dan Wang, and Kai Li \\ Research Institute of Pomology, Tianjin Academy of Agricultural Sciences/ \\ Tianjin Facility Agriculture Research Institute/Tianjin Modern Agricultural \\ Science and Technology Innovation Base Management Center, Tianjin \\ 301700, China
}

Additional index words. pruning recycling, root system, soil properties, bacterial community, high-throughput sequencing

\begin{abstract}
The addition of pulverized grape pruning wood to grape soils has a positive effect on fruit quality. However, its effects on the soil microecology of the root zone and the growth of the grape plants are not fully understood. To address this, 'Shine Muscat' grapes were cultivated in media consisting of garden soil and crushed grape pruning material at different mass ratios [100:1 (T1), 50:1 (T2), 30:1 (T3), 20:1 (T4), and 10:1 (T5)] and in garden soil without the pruning material, as a control. The changes in the plant fresh weight, leaf area, soil and plant analyzer development (SPAD) value, root development, soil organic carbon, microbial biomass carbon, and soil enzyme activity were determined over time. High-throughput sequencing technology was used to determine the soil bacterial community structures. The pruning supplementation increased the grape plants fresh weight, leaf area, and SPAD values. The T2 and T3 treatments increased the grape root length, surface area, and the projected area and number of the root tips; the soil organic carbon content, microbial biomass carbon content, soil invertase activity, amylase activity, and $\beta$-glucosidase activity were also significantly increased. The addition of the grape pruning material was found to increase the bacterial diversity and richness 60 and 150 days after treatment. At the phylum level, Proteobacteria, Acidobacteria, and Actinobacteria were the dominant groups, and the grape pruning material increased the relative abundance of the Acidobacteria and Actinobacteria after 60 and 150 days. The relative abundance of the Actinobacteria in the T2 treatment was $1.7,1.3,1.5$, and 1.3 times that of the control, after $60,90,120$, and 150 days, respectively. The $T 2$ treatment was identified as the optimal treatment for grapes in the field because it improved the soil microecology and promoted root and tree development the most compared with the other treatments tested.
\end{abstract}

In production, the long-term use of inorganic fertilizers, tillage practices, the removal of pruned material, high-density cultivation, and high harvest indices have resulted in the loss of large amounts of soil organic carbon, and measures are now required to increase it (Bhattacharya et al., 2016; Fan et al., 2005; Montanaro et al., 2012). Many previous studies have shown

Received for publication 27 Aug. 2020. Accepted for publication 13 Oct. 2020.

Published online 12 November 2020

This work was funded by the Young Elite Scientists Sponsorship Program by CAST (No. 2018QNRC001), the Tianjin Innovative Research and Experiment Project for Young Researchers (No. 201914), and the Tianjin Science and Technology Planning Project (18YFYZCG00020).

H.S. is the corresponding author. E-mail: suhong 19871014@126.com

This is an open access article distributed under the CC BY-NC-ND license (https://creativecommons. org/licenses/by-nc-nd/4.0/). that returning plant residues to the field alters the labile organic carbon components of the soil and can optimize soil structures, promote nutrient cycling, and increase the availability of nutrients, thereby improving the soil's fertility level (Chapin, 1980; Emmerling et al., 2002; Huang et al., 2008; Ramos et al., 2010; Shao et al., 2009; Singh et al., 2007).

The soil's microecological environment is formed by the combined action of plants, soil microorganisms, and soil. The type and quantity of soil microorganisms and the activity of enzymes in the soil can reflect various minor changes in the soil organic matter, and can have a direct effect on the formation of soil organic matter and soil aggregation, which ultimately affects the growth of plants (Sparling, 1992; Veen et al., 1985). The diversity of the soil microbial community structures plays an important role in maintaining the functions of the soil ecosystem (Young and Crawford, 2004).

Numerous studies have shown that there is a mutually beneficial relationship between the incorporation of plant residues into the soil and soil microorganisms. Plant residues act as organic modifiers and can improve soil fertility, increase microbial biomass, and promote the improvement of soil microbial activity and changes in soil microbial community structures (Perezlomas et al., 2010; Torres et al., 2015; Yu et al., 2008). In addition, the increase of soil microorganisms and the water-retaining effect of the returned materials can promote the growth of plant roots, which can indirectly promote tree growth and yield increases (Aslantas et al., 2007). Moralescorts et al. (2014) found that using green and pruning wastes as compost materials to produce plant growth media could significantly promote the growth of Leyland cypress, petunia, and pansy. Mbuthia et al. (2015) also pointed out that after degrading the residues of hairy vetch, the soil quality could be improved by $4.6 \%$, and the production of cotton crops could be guaranteed without adding any inorganic nitrogen fertilizer.

Vine pruning produces a large amount of waste each year. The pruning material is rich in organic matter and various inorganic nutrients. It is often used as fuel for direct combustion, but this not only wastes nutrients but also produces carcinogenic pollutants during the combustion process (Kjallstrand et al., 1998). In the United States, Australia, New Zealand, and other countries, the use of grape pruning compost to cover vineyards can effectively increase fruit yields, reduce fruit $\mathrm{pH}$, and increase the fruits potassium content (Chan et al., 2010). Gaiotti et al. (2017) pointed out that the use of compost made from grape pruning wastes in vineyards could have a beneficial effect on soil fertility, root growth, yield, and grape quality. Therefore, how to rationally use the waste pruning material of the grapes and other fruit trees should be investigated further.

There have been previous reports on the effects that returned pruning materials will have on the soil microecology and plant growth. However, it is known that returning different types of plant pruning materials will have different effects on the soil's microecological environment because of their different plant tissues, debris quantities, and qualities (Reich et al., 2005). Uselman et al. (2012) also concluded that differences in the plant materials could affect carbon sources and nutrient cycling in the soil. The addition of these carbon substrates will change the original community structures of the soil and result in different degradation functions (Torres et al., 2014).

In view of the fact that grape pruning materials have a positive effect and improve the quality of grapes, it is necessary for us to study the characteristics of the soil microbial community structures and carbon metabolism in the grape root zone after its addition. Therefore, in this experiment, grape pruning material was applied at different doses as a growth media for 1-year-old 'Shine Muscat' grapes. The objective of this work was to investigate the effects that the 
grape pruning material had on the grape tree growth, root development, soil enzyme activity, and soil microbial community structures, to determine the appropriate dosages for the material. Experiential results suggest an alternative use for grape pruning materials and a theoretical basis for the soil microecological changes that occur after their addition.

\section{Materials and Methods}

Materials and treatment. The experiment was conducted from March to August in 2019, at the solar greenhouse of Tianjin Academy of Agricultural Sciences, located in northern China (lat. $39^{\circ} 43^{\prime} \mathrm{N}$, long. $\left.116^{\circ} 96^{\prime} \mathrm{E}\right)$. One-year-old grape pruning material was crushed using a pruning crusher (38.5 KW/380 V) produced by Shanghai Yuchang Garden Engineering Co., Ltd. The average length of the crushed grape prunings was 0.5 to $1 \mathrm{~cm}$. The garden soil used for cultivation in these experiments was sourced from the 'Shine Muscat' grape plots to ensure that it accurately reflected the soil microbial metabolic characteristics of the grapes root zones. To do this, the litter from the plot was removed, and the soil within a 1-m radius of the trunk of a 'Shine Muscat' grape, at a depth of 10-40 cm, was removed without the stones and grape roots, then mixed well and sieved (sieve diameter $=6 \mathrm{~mm}$ ). The chemical characteristics of the cultivated garden soil were $\mathrm{pH} 7.35,40.95 \mathrm{mg} \cdot \mathrm{kg}^{-1}$ available nitrogen, $32.06 \mathrm{mg} \cdot \mathrm{kg}^{-1}$ available phosphorus, and $124.79 \mathrm{mg} \cdot \mathrm{kg}^{-1}$ available potassium. The cultivated garden soil and crushed grape pruning material were mixed evenly according to a mass ratio of 100:1 (T1), 50:1 (T2), 30:1 (T3), 20:1 (T4), and 10:1 (T5) to be used as growing media, and the garden soil alone was used as a control (CK). In Mar. 2019, high-quality 'Shine Muscat' grape seedlings with uniform growth and no pests or diseases were selected and planted in plastic pots (top diameter $=30 \mathrm{~cm}$, bottom diameter $=20 \mathrm{~cm}$, depth $=30 \mathrm{~cm}$, volume $=15 \mathrm{~L}$ ) containing the above growing media for routine management. The experiment included six treatments, each with 48 plants, for a total of 288 seedlings. After planting for $60,90,120$, and $150 \mathrm{~d}$, the seedlings were harvested accordingly for the detection of various indicators. In this experiment, each treatment was arranged in a completely randomized design with three replicates. First, 12 plants were randomly harvested from each treatment during each sampling period. Second, every four plants were mixed as one repetition for a total of three repetitions (Supplemental Fig. 1).

Soil sampling method. As shown in Supplemental Fig. 1, for each sampling period, the 12 seedlings of each treatment were randomly divided into three groups (three repetitions), with four seedlings in each group (one repetition). The plastic pots for the four seedlings per group were removed and the soil loosened; impurities such as the roots and litter were then also removed, and the samples were passed through a 1-mm sieve and mixed thoroughly as a soil sample (one repetition). The samples were each divided into three parts, according to the quartile method, and quickly brought back to the laboratory in an icebox and stored at $-80{ }^{\circ} \mathrm{C}$ or $4{ }^{\circ} \mathrm{C}$ until further analysis. The remaining soil samples were naturally dried, ground, and sieved and used to determine the basic physical and chemical properties of the soil.

Methodology. The fresh weight of the plants was determined using an electronic balance (ES20K-1D; Zhengzhou Nanbei Instrument Equipment Co., Zhengzhou, China). The leaf area was measured using a portable leaf area meter (CI-202; CID Bio Science, Inc., Camas, WA), and the leaf SPAD value was measured with a chlorophyll meter (SPAD-502; Minolta Co., Japan). Root length, surface area and projected area, and the number of root tips were scanned and analyzed using a root analysis system (WinRHIZO; Regent Instruments Canada Inc., Quebec, Canada).

Soil organic carbon content was determined using potassium dichromate oxidationspectrophotometry (National Environmental Protection Standard of the People's Republic of China, 2011). In this procedure, $0.1 \mathrm{~g}$ of mercury sulfate and $5 \mathrm{~mL}$ of $0.27 \mathrm{~mol} \cdot \mathrm{L}^{-1}$ $\mathrm{K}_{2} \mathrm{Cr}_{2} \mathrm{O}_{7}$ were added to $0.05 \mathrm{~g}$ of soil and shaken well; $7.5 \mathrm{~mL}$ of $1.84 \mathrm{~g} \cdot \mathrm{mL}^{-1} \mathrm{H}_{2} \mathrm{SO}_{4}$ was then slowly added. This mixture was digested at $135{ }^{\circ} \mathrm{C}$ for $30 \mathrm{~min}$, then cooled in a water bath and brought to a volume of 100 $\mathrm{mL}$ with distilled water. After leaving the mixture to clarify, the absorbance of the supernatant was measured at $585 \mathrm{~nm}$. The soil microbial biomass carbon content was determined using chloroform fumigation with a total organic carbon analyzer (Shimadzu TOC-5050A; Shimadzu Corporation SL, Kyoto, Japan) (Vance et al., 1987).

Soil invertase and amylase activities were detected according to the method described by Xu et al. (2004) with some modifications. Briefly, $5 \mathrm{~g}$ of soil was mixed with $15 \mathrm{~mL}$ of $8 \%$ sucrose, $5 \mathrm{~mL}$ of phosphate buffer $(\mathrm{pH}$ 5.5 ), and $0.5 \mathrm{~mL}$ of methylbenzene (for invertase activity assay) or with $15 \mathrm{~mL}$ of acetic acid-phosphate buffer $(\mathrm{pH} 5.6), 0.5$ $\mathrm{mL}$ of methylbenzene, and $10 \mathrm{~mL}$ of $2 \%$ starch (for amylase activity assay). The mixture was incubated at $37^{\circ} \mathrm{C}$ for $24 \mathrm{~h}$ and then filtered. Then, $3 \mathrm{~mL}$ of 3,5-dinitrosalicylic acid (for invertase activity assay) or $2 \mathrm{~mL}$ of 3,5-dinitrosalicylic acid (for amylase activity assay) was added to $1 \mathrm{~mL}$ of the filtrate, boiled in a water bath for $5 \mathrm{~min}$, taken out to cool, and brought to the volume of $50 \mathrm{~mL}$ with distilled water. The absorbance was measured at $508 \mathrm{~nm}$. Invertase and amylase activities were expressed as $\mathrm{mg} \cdot \mathrm{d}^{-1} \cdot \mathrm{g}^{-1}$. Soil cellulase activity was measured according to Torres et al. (2015), using carboxymethylcellulose as a substrate. The cellulase activity was expressed as $\mathrm{mg} \cdot \mathrm{d}^{-1} \cdot \mathrm{g}^{-1}$. Soil $\beta$-glucosidase activity was determined using the method described by Torres et al. (2015), with some modifications. The soil $(0.5 \mathrm{~g})$ was mixed with $2 \mathrm{~mL}$ of modified universal buffer $\left(\mathrm{pH}\right.$ 6) and $0.5 \mathrm{~mL}$ of $0.025 \mathrm{~mol} \cdot \mathrm{L}^{-1} \mathrm{p}$ - nitrophenyl $\beta$-D-glucopyranoside. The mixture was shaken at $37^{\circ} \mathrm{C}$ for $1 \mathrm{~h}$, followed by a $90{ }^{\circ} \mathrm{C}$ water bath for $5 \mathrm{~min}$. The enzymatic reaction was ended with cool running water, centrifuged at $10000 \times \mathrm{g}$ for $10 \mathrm{~min}$, at $25{ }^{\circ} \mathrm{C}$. Then, $2 \mathrm{~mL}$ of $0.1 \mathrm{~mol} \cdot \mathrm{L}^{-1}$ tris aminomethane-sodium hydroxide $(\mathrm{pH} 12)$ was added. $\beta$-glucosidase activity was assayed by monitoring the formation of $p$ nitrophenol at $400 \mathrm{~nm}$. The $\beta$-glucosidase activity was expressed as $\mu \mathrm{mol} \cdot \mathrm{d}^{-1} \cdot \mathrm{g}^{-1}$.

The cetyl trimethyl ammonium bromide method was used to extract the genomic DNA from the soil samples, and the DNA purity and concentrations were analyzed using $1 \%$ agarose gel electrophoresis. To study the bacterial community structures and compositions, the DNA samples were sent to Novogene Bioinformatics Technology Co. Ltd. (Beijing, China) for high-throughput sequencing of the 16S rRNA amplicons. The V4 region of the 16S rRNA genes was amplified using the following primers: $515 \mathrm{~F}$ (5'-GTGCCAGCMGCCGCGGTAA-3') and 806R (5'-GGACTACHVGGGTWTCTAAT$\left.3^{\prime}\right)$. All polymerase chain reactions (PCRs) were performed using specific primers with the barcode and Phusion High-Fidelity PCR Master Mix with GC Buffer (New England Biolabs). The PCR products were detected by electrophoresis using 2\% agarose gel and purified with the Qiagen Gel Extraction Kit (Qiagen, Hilden, Germany). The TruSeq DNA PCR-Free Sample Preparation Kit was used for the generation of the sequencing library. Qubit and Q-PCR were applied to assess the quality of the library. Afterward, the library was sequenced on a NovaSeq6000 platform. Each soil sample was subjected to three biological replicate tests. Barcode and primer sequences were cut off from the paired-end reads, and the paired-end reads of each sample were merged using FLASH (V1.2.7). Qiime (V1.9.1) quality control processes were used to obtain clean tags. The clean tags were compared with the gold database using the UCHIME algorithm to remove chimera sequences and obtain the effective tags. Effective tags for all samples (sequences at the $97 \%$ similarity level) were assigned to the same operational taxonomic units (OTUs) using the Uparse software (v7.0.1001). To annotate taxonomic information, the representative sequences of each OTU were assigned using the method of Mothur by searching against the SSU rRNA database (Wang et al., 2007) of SILVA132 (Edgar, 2013). The Qiime software (Version 1.9.1) was used to calculate the observed OTUs, Chao1, Shannon, Simpson, and ACE indices and to build an unweighted pair-group method with arithmetic means (UPGMA) clustering.

Statistical analysis. Statistical analysis was performed with the IBM SPSS Statistics data processing software (version 21.0; IBM, Armonk, NY). A completely randomized design was used in this study. One-way analysis of variance was applied with the grape pruning supplement treatment as the only factor. Differences between the treatments 
were analyzed using the Duncan's multiple range test, at a significance level of $P<0.05$. $\mathrm{R}$ software (Version 2.15.3) was used to analyze the differences between the groups based on their alpha diversity indices, to plot the rarefaction curve, Venn graph, and relative abundances of the soil bacteria per genus, and for the principal coordinate analysis (PCoA). The column chart was generated using Microsoft Excel software (version 2010; Microsoft Corp., Redmond, WA). The data in this study are expressed as mean \pm SD. All experiments were performed in triplicate, except for the SPAD value, which was repeated five times.

\section{Results}

Effects of the grape pruning supplements on plant growth and development. Compared with the $\mathrm{CK}$, the $\mathrm{T} 1, \mathrm{~T} 2$, and $\mathrm{T} 3$ treatments increased the fresh weights of the grape plants but not significantly. Furthermore, compared with the $\mathrm{CK}$, the $\mathrm{T} 2$ treatment increased the leaf area and SPAD values of the grapes, but not significantly. In contrast, the T4 and T5 treatments significantly reduced the plant fresh weight and SPAD values (Fig. 1).

Effects of the grape pruning supplements on the morphological development of the grape roots. Compared with the $\mathrm{CK}$, the $\mathrm{T} 2$ and $\mathrm{T} 3$ treatments increased the grape root length, surface area, and the projected area and number of the root tips, with the T2 treatment having the most significant effects. In contrast, root development was blocked after the T4 and T5 treatments (Fig. 2).

Effects of the grape pruning supplements on soil organic carbon and microbial biomass carbon content. Except for the T1
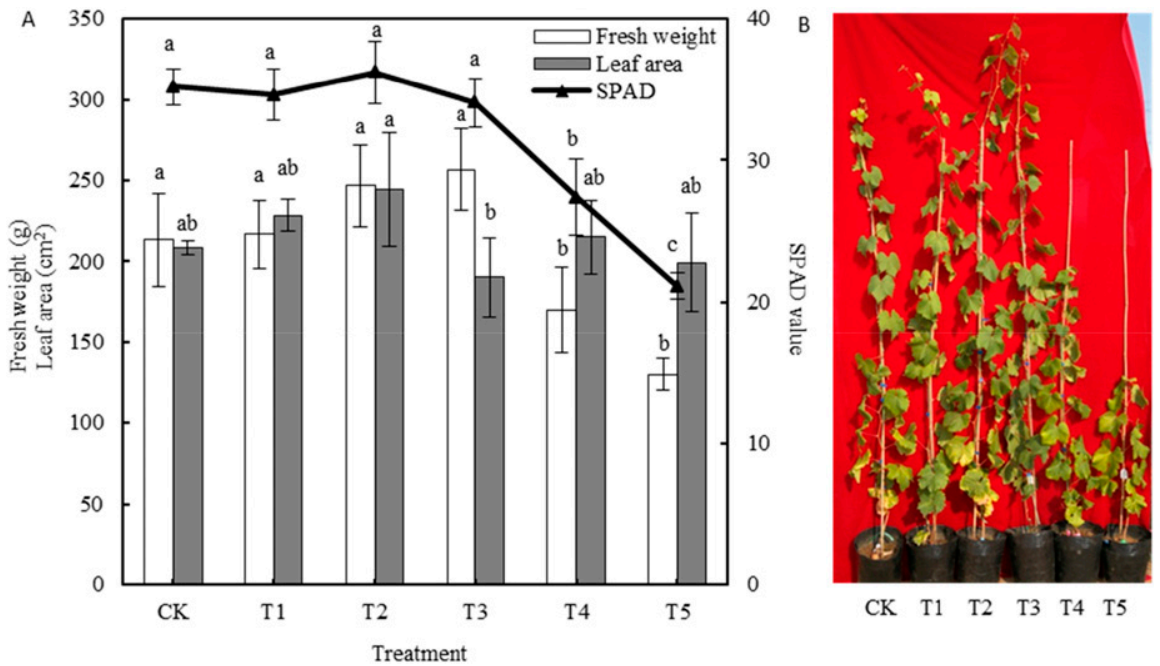

$\begin{array}{llllll}\text { CK } & \text { T1 } & \text { T2 } & \text { T3 } & \text { T4 } & \text { T5 }\end{array}$

Fig. 1. Fresh weight, leaf area, and SPAD value with different proportions of the grape pruning material in the substrates. CK (the garden soil cultivation alone), T1 (cultivated garden soil to crushed grape prunings $=100: 1)$, T2 (cultivated garden soil: crushed grape prunings $=50: 1)$, T3 (cultivated garden soil: crushed grape prunings $=30: 1)$, T4 (cultivated garden soil: crushed grape prunings $=20: 1$ ), T5 (cultivated garden soil: crushed grape prunings $=10: 1)$. The data in the figure are mean $\pm \mathrm{SD}($ fresh weight and leaf area, $\mathrm{n}=3$; SPAD value, $\mathrm{n}=5$ ). The lowercase letters indicate the significant differences among treatments $(P<0.05)$. SPAD $=$ soil and plant analyzer development. treatment, all other treatments significantly increased the soil organic carbon (SOC) content throughout the experimental period, and the increases were proportional to the doses of the grape pruning material added. Compared with the $\mathrm{CK}$, the $\mathrm{T} 2, \mathrm{~T} 3$, and $\mathrm{T} 5$ treatments significantly increased the soil microbial biomass carbon (MBC) content throughout the experiment. Of the three treatments, the highest MBC content was observed with the T2 treatments, after both 90 and $120 \mathrm{~d}$ (Fig. 3).

Effects of the grape pruning supplements on soil enzyme activity. Compared with the $\mathrm{CK}$, the T2 and T3 treatments significantly improved the soil invertase and amylase activities throughout the experiment, but the effects of the T1 treatments were the opposite. The T5 treatment significantly inhibited soil invertase and amylase activities after both 60 and $90 \mathrm{~d}$. Compared with the CK, each treatment significantly reduced the soil cellulase activity after $150 \mathrm{~d}$, and the T2 treatment significantly increased the soil cellulase activity after both 90 and $120 \mathrm{~d}$. The T5 treatment significantly reduced the soil cellulase activity throughout the experiment. Compared with the CK, the T2 and T3 treatments improved the soil $\beta$-glucosidase activity throughout the experiment (Fig. 4).

Analysis of the soil sample sequencing depths. The rarefaction curve can directly reflect the rationality of the amount of sequencing data and indirectly reflect the richness of the species in the sample. It can be seen from Fig. 5 that with increased sequencing, the curve gradually flattens, and the number of OTUs tends to be saturated, indicating that the amount of sequencing data in this experiment was reasonable and that more data would result in only a small number of additional new species being identified.

Effects of grape pruning supplementation on soil bacterial alpha diversity. The alpha diversity index is an indicator used to effectively evaluate the diversity and species richness of soil microbial communities (Caporaso et al., 2010). It can be seen from Fig. 6, that
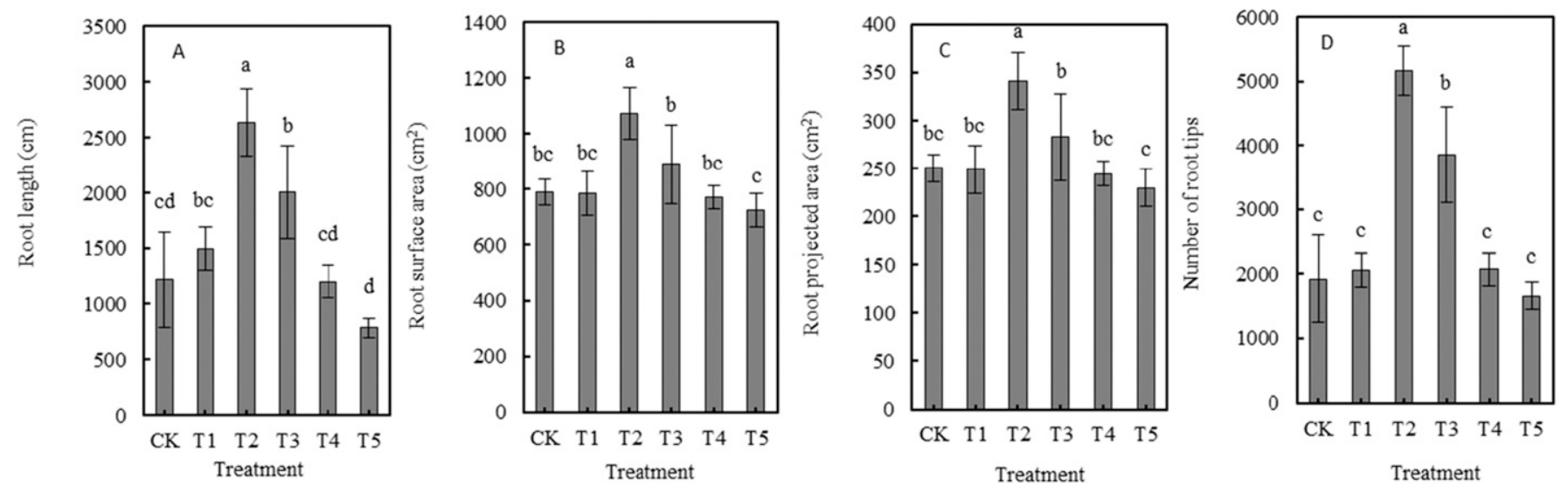

Fig. 2. Root length (A), surface area (B), projected area $(\mathbf{C})$, and number of root tips $(\mathbf{D})$ with the different doses of the grape pruning material in the substrates. CK (the garden soil cultivation alone), T1 (cultivated garden soil: crushed grape prunings $=100: 1$ ), T2 (cultivated garden soil: crushed grape prunings $=50: 1$ ), T3 (cultivated garden soil: crushed grape prunings $=30: 1)$, T4 (cultivated garden soil: crushed grape prunings $=20: 1)$, T5 $($ cultivated garden soil: crushed grape prunings $=$ 10:1). The data in the figure are mean $\pm \mathrm{SD}(\mathrm{n}=3)$. The lowercase letters in the figure indicate the significant differences among the treatments $(P<0.05)$. 


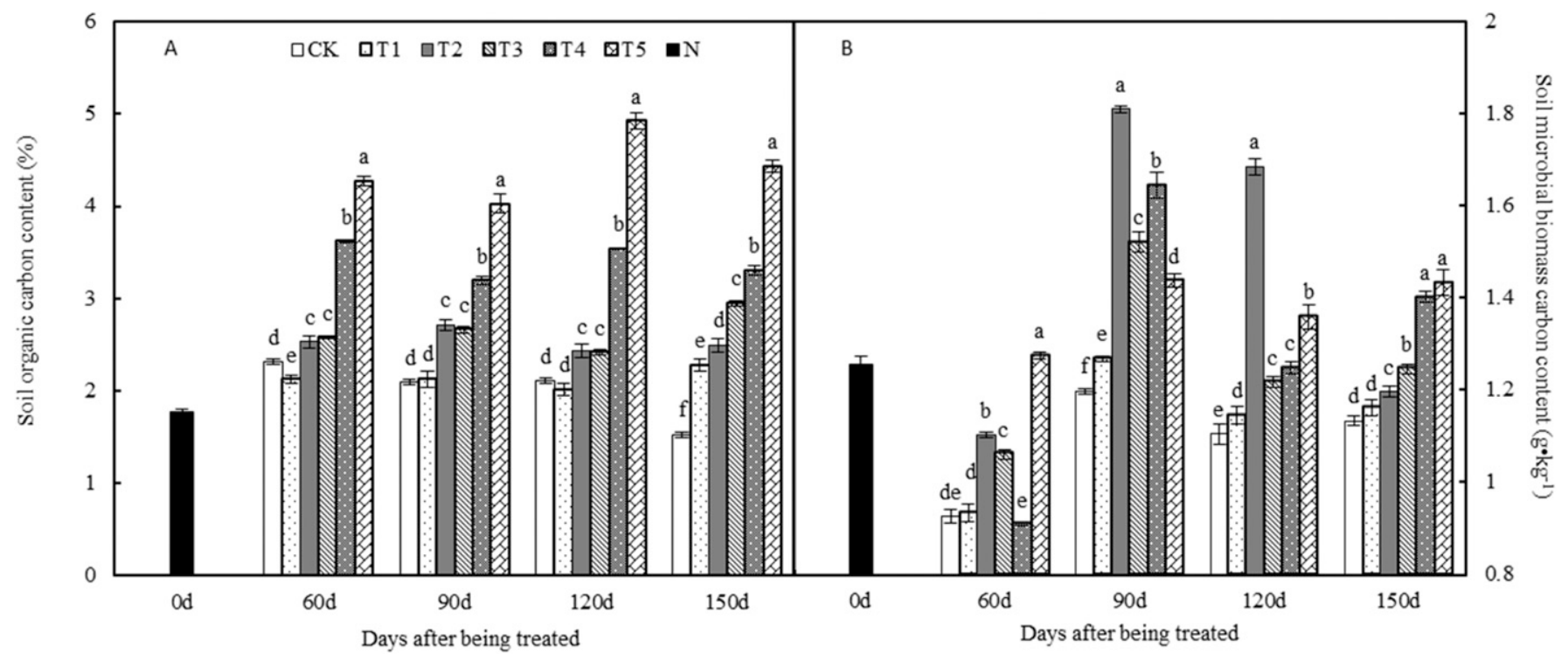

Fig. 3. Soil organic carbon (A) and microbial biomass carbon content $(\mathbf{B})$ with the different doses of the grape pruning material in the substrates. CK (the garden soil cultivation alone), T1 (cultivated garden soil: crushed grape prunings $=100: 1), \mathrm{T} 2$ (cultivated garden soil: crushed grape prunings $=50: 1)$, T3 $($ cultivated garden soil: crushed grape prunings $=30: 1), \mathrm{T} 4$ (cultivated garden soil: crushed grape prunings $=20: 1), \mathrm{T} 5$ (cultivated garden soil: crushed grape prunings $=$ $10: 1), \mathrm{N}$ (garden soil cultivation alone before treatment). The data in the figure are mean $\pm \mathrm{SD}(\mathrm{n}=3)$. The lowercase letters indicate the significant differences among treatments in the same period $(P<0.05)$.

the total number of OTUs shared between the different treatments was 2877 after $150 \mathrm{~d}$. The unique OTUs for each treatment were 498 (CK), 609 (T1), 920 (T2), 336 (T3), 474 (T4), and 931 (T5). Overall, with the increased grape pruning doses, the number of unique OTUs in each treatment showed a trend of first increasing, then decreasing, and then increasing. This means that the sequence similarity of the soil bacterial community compositions between those with the added pruning material and the $\mathrm{CK}$ changed. Among them, the T1, T2, and T5 treatments increased the number of soil-specific bacterial species in the root zone.

In this experiment, the alpha diversity index of the different samples at $\approx 97 \%$ were counted (Table 1). Compared with the CK, the treatments with the different amounts of pruning materials (T1-T5) increased the actual observed OTUs, Shannon index, Simpson index, Chao1 index, and ACE index of the soil bacterial communities after both 60 and $150 \mathrm{~d}$. Sixty days after the T2 and T3 treatments, the diversity and richness of the soil bacterial communities were significantly higher than those in the CK. One-hundred and fifty days after the $\mathrm{T} 1, \mathrm{~T} 4$, and $\mathrm{T} 5$ treatments, the diversity and richness of the soil bacterial communities were significantly increased. Treatments T1-T5 had different effects on the number of the soil bacterial community OTUs, Shannon index, Simpson index, Chaol index, and ACE index after both 90 and $120 \mathrm{~d}$, but the differences were not significant compared with the CK.

Effects of the grape pruning supplements on soil bacterial community structure and composition. The analysis of the compositions of the soil bacterial communities found that at the phylum level, the 10 phyla with the highest relative abundances of all soil samples were Proteobacteria, Firmicutes, Acid- obacteria, Actinobacteria, Bacteroidetes, Gemmatimonadetes, Planctomycetes, Verrucomicrobia, Chloroflexi, and Thaumarchaeota. Proteobacteria, Acidobacteria, and Actinobacteria had the highest relative abundances and belonged to the dominant bacterial group. All treatments with added pruning material reduced the relative abundances of the Proteobacteria after both 60 and $150 \mathrm{~d}$ but increased the relative abundances of the Acidobacteria and Actinobacteria. Each treatment had different effects on the bacterial communities after both 90 and $120 \mathrm{~d}$. Among them, compared with the CK, the T2 treatment significantly increased the relative abundance of the Actinobacteria after 90 and 120 d by $31.59 \%$ and $47.35 \%$, respectively (Fig. 7).

The treatments with the different amounts of pruning material (T1-T5) mainly reduced the relative abundances of the soil Ralstonia, Alcaligenes, and Stenotrophomonas and increased the relative abundances of the Pseudomonas, Methylobacillus, Devosia, unidentified_Gammaproteobacteria, Dongia, Skermanella, Pseudoxanthomonas, Haliangium, Sphingomonas, and Pseudoduganella after both 60 and $150 \mathrm{~d}$. At the same time, the T1-T5 treatments also increased the relative abundance of the soil Bryobacter, unidentified_Acidobacteria, Gaiella, and Aeromicrobium after both 60 and $150 \mathrm{~d}$. Among them, the T2 treatment not only improved the relative abundance of the soil Aeromicrobium, Gaiella, Sporosarcina, Bryobacter, Bacillus, and unidentified_Nitrospiraceae during the entire experiment, but also significantly increased the relative abundances of the Bacteroides, Subdoligranulum, and unidentified_Lachnospiraceae after $150 \mathrm{~d}$ by 6.4, 22.7, and 39.3 times compared with that of the CK, respectively (Fig. 8).

The PCoA for the soil bacteria with the different pruning treatments is shown in
Fig. 9. Different treatments had different effects on the soil bacterial community structures. After $60 \mathrm{~d}$ of treatment, the distances between the soil sample points from those with added pruning materials and the CK sample points were large, indicating that the addition of the pruning material changed the soil bacterial community compositions. Among them, the sample points of T1, T2, and T3 were close to each other, indicating that the compositions of the soil bacterial communities treated using $\mathrm{T} 1, \mathrm{~T} 2$, and $\mathrm{T} 3$ were similar at this time. After $90 \mathrm{~d}$ of treatment, the distances between the CK and the $\mathrm{T} 1, \mathrm{~T} 2$, and T3 treatment sample points were reduced, indicating that the soil bacterial community compositions tended to be similar at this time. After $120 \mathrm{~d}$ of treatment, the soil bacterial communities in the $\mathrm{T} 1$ treatment were significantly different from those of the other treatments, and the bacterial communities in the T2 and T3 treatments were more similar. After $150 \mathrm{~d}$ of treatment, the bacterial community compositions of the $\mathrm{T} 1$ and $\mathrm{T} 2$ treatments tended to be similar but different from those of the $\mathrm{CK}$ and $\mathrm{T} 3$ treatments. It can be seen from Figs. 9 and 10 that the sample point distances of the T4 and T5 treatments were relatively close during the experiment (from 60 to $120 \mathrm{~d}$ ), but far from those of the other treatments. It can also be seen from the UPGMA cluster analysis that the T4 and T5 treatments were grouped during the entire experiment, indicating that the two treatments had high similarity and obviously changed the structures of the soil bacterial communities.

\section{Discussion}

Grape pruning supplements influenced root development. Plant roots are direct sensors of the changes in the soil environment 


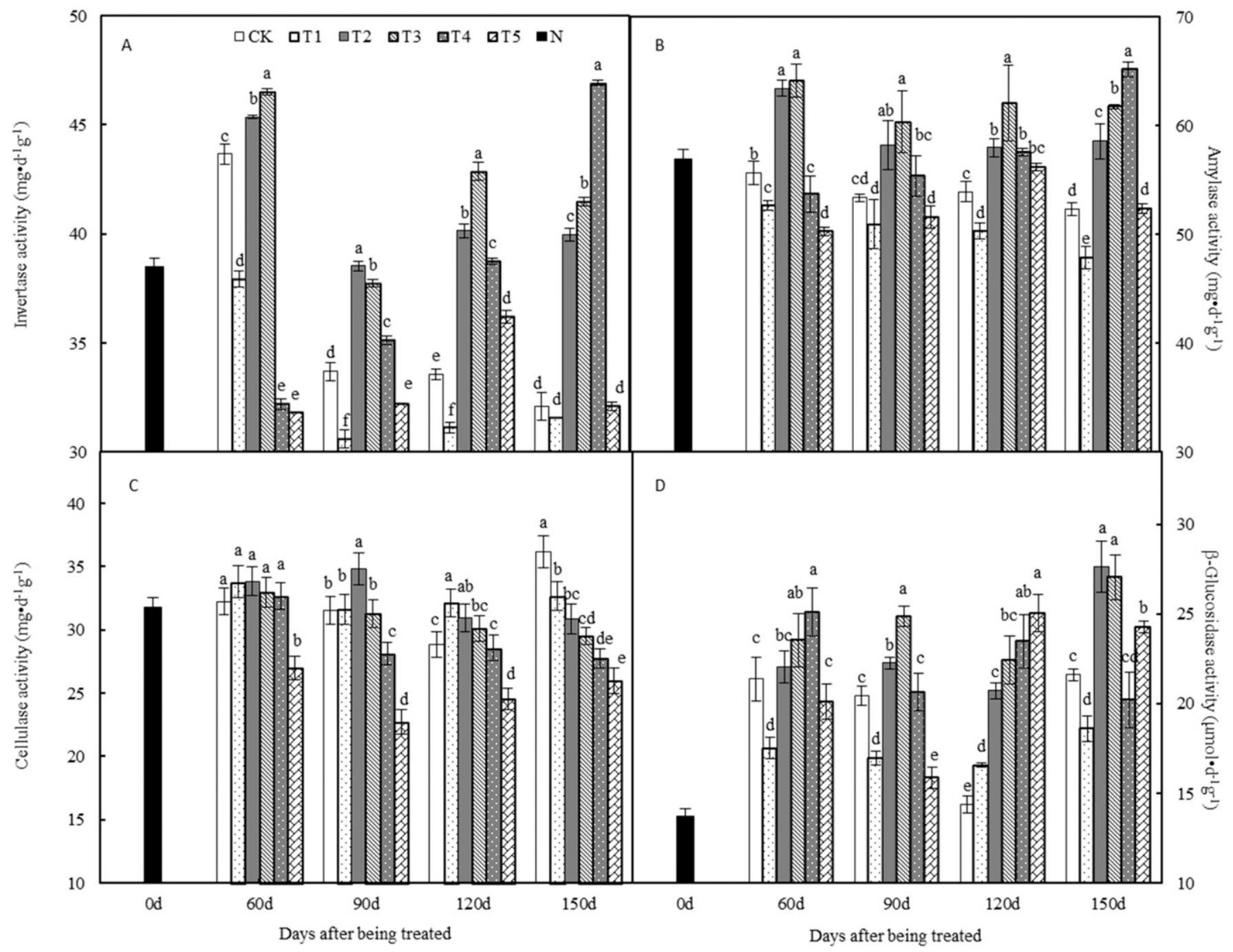

Fig. 4. Soil enzyme activities with the different doses of the grape pruning material in the substrates. CK (garden soil cultivation alone), T1 (cultivated garden soil: crushed grape prunings $=100: 1$ ), T2 (cultivated garden soil: crushed grape prunings $=50: 1$ ), T3 (cultivated garden soil: crushed grape prunings $=30: 1$ ), T4 (cultivated garden soil: crushed grape prunings $=20: 1$ ), T5 (cultivated garden soil: crushed grape prunings $=10: 1$ ), $\mathrm{N}$ (garden soil cultivation alone before treatment). The data in the figures are the mean $\pm \mathrm{SD}(\mathrm{n}=3)$. The lowercase letters indicate the significant differences among the treatments in the same period $(P<0.05)$.

(Lynch and Brown, 2012). A plant's physiological metabolism, growth, and distribution are affected by the carbon sources in the substrate, which can indirectly reflect the growth and development of the plant, and ultimately affect crop yields (Jin et al., 2009). It is well known that the root systems are affected by the heterogeneity of soil resources, and their morphologies will adjust significantly with changes in the soil environment (Hodge, 2006). This shows both morphological and physiological plasticity, to enhance the nutrient resource capture, which is the modular nature of root systems. Furthermore, the proliferation of the root system will lead to an increase in the root exudation/secretion processes, thereby providing fuel for the microbial biomass and thus enhancing microbial populations in the soil. Mininni et al. (2012) found that compost containing olive pruning could significantly increase the fresh weight, leaf area, root length, root surface area, and number of root tips of lettuce plants. Mininni et al. (2013) also found that the application of compost containing grapevine prunings to tomato seedlings could significantly increase the total root length, root surface area, and root volume. Lyu (2017) found that returning apple pruning material to fields increased the biomass, leaf area, total root length, and number of the root tips of the apple rootstock, compared with the control (without pruning material). Gaiotti et al. (2017) found that the under-row application of compost from the vine pruning waste significantly increased the total root density of the fine roots $(<1 \mathrm{~mm})$, medium roots $(1-2 \mathrm{~mm})$, and the vertical and horizontal distribution of the root systems. The results of this study are in line with previous investigations - that is, appropriate grape pruning addition (T2) treatments could significantly improve the grape root length, root surface area, and number of the root tips, to some extent. Root morphology determines the amount of soil that can be

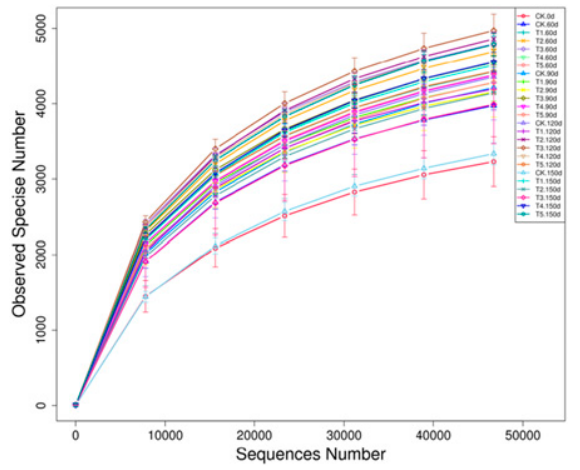

Fig. 5. Bacterial rarefaction curves from the soil samples taken from the grape root zone. CK (garden soil cultivation alone), T1 (cultivated garden soil: crushed grape prunings $=100: 1$ ), T2 (cultivated garden soil: crushed grape prunings $=50: 1$ ), T3 (cultivated garden soil: crushed grape prunings $=30: 1)$, T4 (cultivated garden soil: crushed grape prunings $=20: 1$ ), T5 (cultivated garden soil: crushed grape prunings $=$ 10:1). $60 \mathrm{~d}, 90 \mathrm{~d}, 120 \mathrm{~d}$, and $150 \mathrm{~d}$ indicate days after the treatment. 
exploited by plants, which in turn affects the nutrient and water absorption, and the development of the entire plant (Lazcano et al., 2009). In this study, the T2 treatment (garden soil: grape prunings $=50: 1$ ) increased the grape biomass, leaf area, and SPAD value which also confirms previous findings. On the contrary, the T4 and T5 treatments significantly reduced the plant fresh weight and

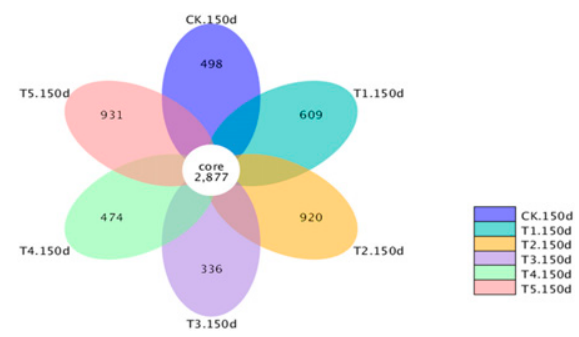

Fig. 6. Venn diagrams of the bacterial operational taxonomic unit (OTU) distributions in the soils with the different doses of the additional pruning material. CK (garden soil cultivation alone), T1 (cultivated garden soil: crushed grape prunings $=100: 1)$, T2 $($ cultivated garden soil: crushed grape prunings $=50: 1$ ), T3 (cultivated garden soil: crushed grape prunings = 30:1), T4 (cultivated garden soil: crushed grape prunings $=20: 1$ ), T5 (cultivated garden soil: crushed grape prunings $=10: 1$ ). The data in the Venn diagram were taken $150 \mathrm{~d}$ after the treatment with the grape pruning. Effective tags for all samples (sequences at the 97\% similarity level) were assigned to the same OTUs using the Uparse software (Uparse v7.0.1001). The numbers in the petals represent unique OTUs between different samples. The number in the center of the flower represents the OTUs shared between different samples.
SPAD, which were related to the high soil carbon to nitrogen ratio $(\mathrm{C} / \mathrm{N})$ after adding high concentrations of grape pruning material. Previous studies have indicated that when soil has a high $\mathrm{C} / \mathrm{N}$, the mineralization of organic materials competed with plants for nitrogen, which affected the growth and development of the plants (Jiang et al., 2017; Schipper and Sparling, 2011; Springob and Kirchmann, 2003).

$S O C$ and $M B C$ content reflected the dosage of the grape pruning material applied. SOC plays a decisive role in climate regulation, and its dynamic changes greatly affect the formation of soil structures, the stability of soil aggregates, and the biological characteristics of the aboveground plants nutrition (Li et al., 2012; Xi et al., 2011). In farmland soil, the main sources of organic carbon are crop residues, organic fertilizers, and other organic debris (weeds, animals, soil microorganisms, etc.) (Jia et al., 2017). Brunel et al. (2020) found that after a 19-month soil incubation test, the SOC content in the soil in which pruning residues had been returned, was significantly higher than that of the soil without pruning material. At this time, the decomposition and degradation products of the pruning residues had been transferred to the soil. Liu et al. (2019) found that the sequestration of organic carbon in the surface layer of the soil increased with the amount of straw returning. Lyu (2017) also pointed out that adding apple pruning material had a better effect on increasing the SOC content of the orchard soil and on promoting its ecological restoration, when compared with the control (with no pruning material). Similar results were obtained in this study, and except for the $\mathrm{T} 1$ treatment, the other grape pruning addition treatments significantly increased the SOC content and were highly dependent on the dose of the grape pruning material. Previous studies have shown that there was a significant positive relationship between the SOC balance and the addition of organic substances. This is because the addition of exogenous residues can provide a large amount of labile carbon, which may increase the activity of the microorganisms and accelerate the decomposition of the native SOC (positive priming effect) (Qiu et al., 2016).

Soil MBC, as a labile fraction of SOC, is an important indicator used to evaluate the number and activity of soil microorganisms and soil fertility (Nsabimana et al., 2004) and can more sensitively reflect the effect of agronomic management practices over a short period of time (Yang et al., 2017). In this experiment, the $\mathrm{T} 2$, T3, and $\mathrm{T} 5$ treatments significantly increased the MBC content. This is because the input of the exogenous organic matter could provide a sufficient carbon source for the microorganisms and improve the soil microbial activity. Furthermore, the mineralization and release of nutrients and soluble organic matter during the decomposition of crop residues by microorganisms is the main source of labile organic carbon fractions (Guo et al., 2015).

Different doses of grape pruning materials produced different soil enzyme activities. Soil enzymes are an important manifestation of the soil biological functions and play a key role in the biochemical functions of the organic matter decomposition and nutrient cycling (Burns et al., 2013;

Table 1. Soil bacterial community diversity and richness when different amounts of pruning material are added.

\begin{tabular}{|c|c|c|c|c|c|c|}
\hline Duration $^{z}$ & Treatment $^{\mathrm{y}}$ & OTUs & Shannon index & Simpson index & Chaol index & ACE index \\
\hline \multirow[t]{6}{*}{$60 \mathrm{~d}$} & $\mathrm{CK}$ & $3973 \pm 70 \mathrm{~b}$ & $8.80 \pm 0.43 c$ & $0.95 \pm 0.01 \mathrm{~b}$ & $4619 \pm 85 b$ & $4726 \pm 88 \mathrm{~b}$ \\
\hline & $\mathrm{T} 1$ & $4423 \pm 584 \mathrm{ab}$ & $9.99 \pm 0.47 \mathrm{~b}$ & $0.98 \pm 0.01 \mathrm{a}$ & $5108 \pm 757 \mathrm{ab}$ & $5249 \pm 821 \mathrm{ab}$ \\
\hline & $\mathrm{T} 2$ & $4692 \pm 50 \mathrm{a}$ & $10.49 \pm 0.05 \mathrm{ab}$ & $0.99 \pm 0.00 \mathrm{a}$ & $5313 \pm 86 a$ & $5583 \pm 98 \mathrm{a}$ \\
\hline & T3 & $4796 \pm 190 \mathrm{a}$ & $10.54 \pm 0.24 \mathrm{a}$ & $0.99 \pm 0.00 \mathrm{a}$ & $5496 \pm 209 a$ & $5651 \pm 288 \mathrm{a}$ \\
\hline & $\mathrm{T} 4$ & $4540 \pm 107 \mathrm{a}$ & $10.39 \pm 0.01 \mathrm{ab}$ & $0.99 \pm 0.00 \mathrm{a}$ & $5198 \pm 103 \mathrm{ab}$ & $5455 \pm 177 \mathrm{a}$ \\
\hline & T5 & $4381 \pm 66 \mathrm{ab}$ & $10.27 \pm 0.04 \mathrm{ab}$ & $0.99 \pm 0.00 \mathrm{a}$ & $5049 \pm 50 \mathrm{ab}$ & $5256 \pm 115 \mathrm{ab}$ \\
\hline \multirow[t]{6}{*}{$90 \mathrm{~d}$} & CK & $4211 \pm 82 \mathrm{a}$ & $9.82 \pm 0.29 \mathrm{a}$ & $0.99 \pm 0.00 \mathrm{a}$ & $4836 \pm 100 \mathrm{ab}$ & $5096 \pm 143 \mathrm{ab}$ \\
\hline & $\mathrm{T} 1$ & $4276 \pm 301 \mathrm{a}$ & $9.75 \pm 0.59 \mathrm{a}$ & $0.98 \pm 0.01 \mathrm{a}$ & $4908 \pm 325 \mathrm{ab}$ & $5084 \pm 362 \mathrm{ab}$ \\
\hline & $\mathrm{T} 2$ & $4154 \pm 409 a$ & $9.57 \pm 1.38 \mathrm{a}$ & $0.97 \pm 0.03 \mathrm{a}$ & $4769 \pm 452 b$ & $4895 \pm 503 b$ \\
\hline & T3 & $4552 \pm 90 \mathrm{a}$ & $10.44 \pm 0.08 \mathrm{a}$ & $0.99 \pm 0.00 \mathrm{a}$ & $5255 \pm 96 \mathrm{a}$ & $5456 \pm 168 \mathrm{a}$ \\
\hline & $\mathrm{T} 4$ & $4375 \pm 124 \mathrm{a}$ & $10.30 \pm 0.04 \mathrm{a}$ & $0.99 \pm 0.00 \mathrm{a}$ & $5044 \pm 114 \mathrm{ab}$ & $5296 \pm 162 \mathrm{ab}$ \\
\hline & T5 & $4280 \pm 130 \mathrm{a}$ & $10.21 \pm 0.04 \mathrm{a}$ & $0.99 \pm 0.00 \mathrm{a}$ & $4947 \pm 102 \mathrm{ab}$ & $5228 \pm 135 \mathrm{ab}$ \\
\hline \multirow[t]{6}{*}{$120 \mathrm{~d}$} & CK & $4353 \pm 700 \mathrm{ab}$ & $8.76 \pm 2.65 \mathrm{ab}$ & $0.89 \pm 0.17 \mathrm{a}$ & $5054 \pm 718 \mathrm{ab}$ & $5263 \pm 799 a b$ \\
\hline & $\mathrm{T} 1$ & $4193 \pm 262 b$ & $8.25 \pm 0.75 b$ & $0.90 \pm 0.05 a$ & $4654 \pm 519 b$ & $4807 \pm 486 b$ \\
\hline & $\mathrm{T} 2$ & $4860 \pm 104 \mathrm{ab}$ & $10.50 \pm 0.08 \mathrm{a}$ & $0.99 \pm 0.00 \mathrm{a}$ & $5644 \pm 190 \mathrm{a}$ & $5811 \pm 172 \mathrm{a}$ \\
\hline & T3 & $4972 \pm 266 \mathrm{a}$ & $10.40 \pm 0.50 \mathrm{ab}$ & $0.99 \pm 0.01 \mathrm{a}$ & $5724 \pm 348 \mathrm{a}$ & $5928 \pm 422 \mathrm{a}$ \\
\hline & $\mathrm{T} 4$ & $4786 \pm 174 \mathrm{ab}$ & $10.56 \pm 0.07 \mathrm{a}$ & $0.99 \pm 0.00 \mathrm{a}$ & $5519 \pm 197 \mathrm{a}$ & $5699 \pm 193 \mathrm{a}$ \\
\hline & $\mathrm{T} 5$ & $4427 \pm 361 \mathrm{ab}$ & $10.38 \pm 0.19 \mathrm{ab}$ & $0.99 \pm 0.00 \mathrm{a}$ & $5098 \pm 430 \mathrm{ab}$ & $5267 \pm 425 \mathrm{ab}$ \\
\hline \multirow[t]{6}{*}{$150 \mathrm{~d}$} & CK & $3335 \pm 178 b$ & $5.90 \pm 1.18 \mathrm{~b}$ & $0.74 \pm 0.16 b$ & $3942 \pm 141 b$ & $4189 \pm 189 b$ \\
\hline & $\mathrm{T} 1$ & $4510 \pm 37 \mathrm{a}$ & $10.11 \pm 0.08 \mathrm{a}$ & $0.99 \pm 0.00 \mathrm{a}$ & $5204 \pm 133 a$ & $5431 \pm 158 \mathrm{a}$ \\
\hline & $\mathrm{T} 2$ & $4141 \pm 825 \mathrm{ab}$ & $9.11 \pm 1.99 \mathrm{a}$ & $0.96 \pm 0.06 \mathrm{a}$ & $4824 \pm 926 \mathrm{ab}$ & $4991 \pm 990 \mathrm{ab}$ \\
\hline & T3 & $3989 \pm 638 \mathrm{ab}$ & $8.28 \pm 2.19 a$ & $0.88 \pm 0.12 \mathrm{ab}$ & $4577 \pm 693 \mathrm{ab}$ & $4829 \pm 668 \mathrm{ab}$ \\
\hline & $\mathrm{T} 4$ & $4553 \pm 159 a$ & $10.37 \pm 0.18 \mathrm{a}$ & $0.99 \pm 0.00 \mathrm{a}$ & $5270 \pm 256 a$ & $5493 \pm 282 a$ \\
\hline & T5 & $4788 \pm 184 \mathrm{a}$ & $10.51 \pm 0.00 \mathrm{a}$ & $0.99 \pm 0.00 \mathrm{a}$ & $5444 \pm 231 \mathrm{a}$ & $5728 \pm 270 \mathrm{a}$ \\
\hline
\end{tabular}

${ }^{\mathrm{z}} 60 \mathrm{~d}, 90 \mathrm{~d}, 120 \mathrm{~d}$, and $150 \mathrm{~d}$ indicate days after treatments.

${ }^{\mathrm{y}} \mathrm{CK}$ (garden soil cultivation alone), T1 (cultivated garden soil: crushed grape prunings = 100:1), T2 (cultivated garden soil: crushed grape prunings $\left.=50: 1\right)$, T3 (cultivated garden soil: crushed grape prunings $=30: 1)$, T4 (cultivated garden soil: crushed grape prunings $=20: 1)$, T5 (cultivated garden soil: crushed grape prunings $=10: 1)$.

The data in the table are mean $\pm \mathrm{SD}(\mathrm{n}=3)$. The lowercase letters indicate the significant differences among treatments in the same period $(P<0.05)$.

OTUs $=$ operational taxonomic units. 
Tiquia et al., 2002; Waldrop and Firestone, 2004). Soil enzymes are the most effective potential indicators of soil fertility and microbial activity (Badiane et al., 2001) and can be used to assess the effects of organic modifiers on soil characteristics $(\mathrm{Ng}$ et al., 2014). Many studies have pointed out that when pruning waste or straw is returned to

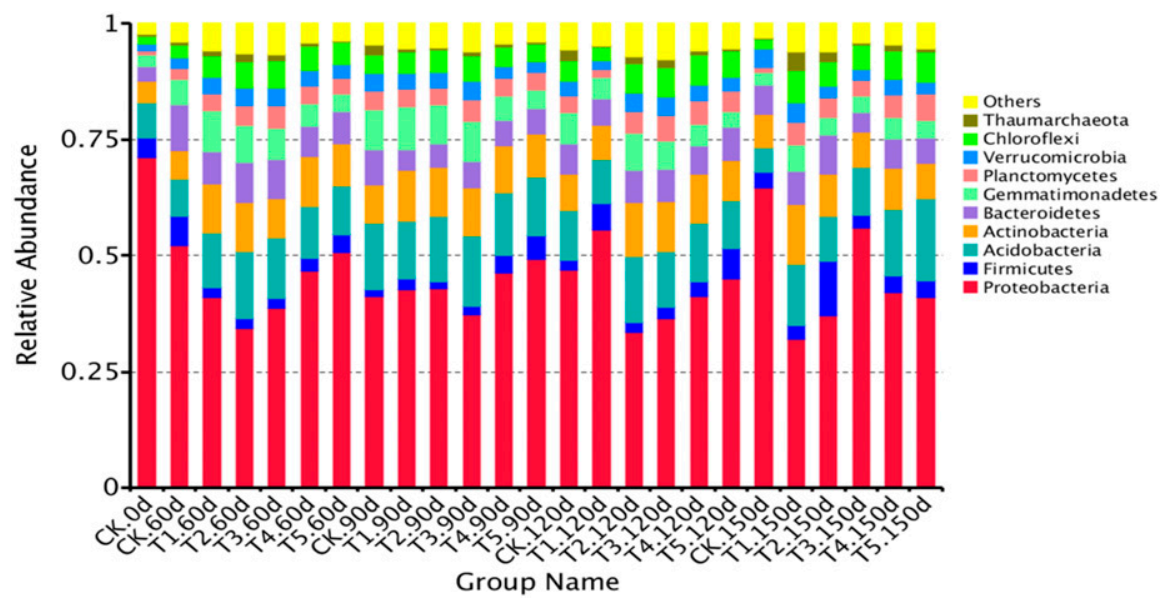

Fig. 7. Taxonomic composition and relative abundances of the soil bacteria phyla with different amounts of the pruning additions. CK (the garden soil cultivation alone), T1 (cultivated garden soil: crushed grape prunings $=100: 1), \mathrm{T} 2($ cultivated garden soil: crushed grape prunings $=50: 1), \mathrm{T} 3($ cultivated garden soil: crushed grape prunings $=30: 1$ ), T4 (cultivated garden soil: crushed grape prunings $=20: 1$ ), T5 (cultivated garden soil: crushed grape prunings $=10: 1) .60 \mathrm{~d}, 90 \mathrm{~d}, 120 \mathrm{~d}$, and $150 \mathrm{~d}$ indicate days after treatments.

the field, it can significantly improve the soil $\beta$-glucosidase activity (Teutscherova et al., 2017; Torres et al., 2015; Zhao et al., 2016, 2019), sucrase activity (Zhao et al., 2019), and cellulase activity (Torres et al., 2015). In this study, it was also found that the $\mathrm{T} 2$ and T3 treatments could increase the soil invertase, amylase, and $\beta$-glucosidase activities but had different effects on the soil cellulase activity in each period. Cellulase is a general term for a group of enzymes that degrade cellulose to produce glucose. At present, it is generally believed that the complete degradation of cellulose requires at least three different but complementary cellulases, namely endoglucanase $(1,4-\beta$-D-glucan glucanohydrolase), exoglucanase $(1,4-\beta$-D-glucan cellobiohydrolase), and $\beta$-glucosidase. This may be the reason for the inconsistent changes in the activities of soil cellulase and $\beta$-glucosidase in this study. In addition, the input of exogenous carbon substrates could stimulate the microbial activity, followed by the secretion of more soil enzyme activity, with the increased addition of carbon (Hojjati and Nourbakhsh, 2007). However, the changes in the soil enzyme activities in this study did not increase in a gradient.

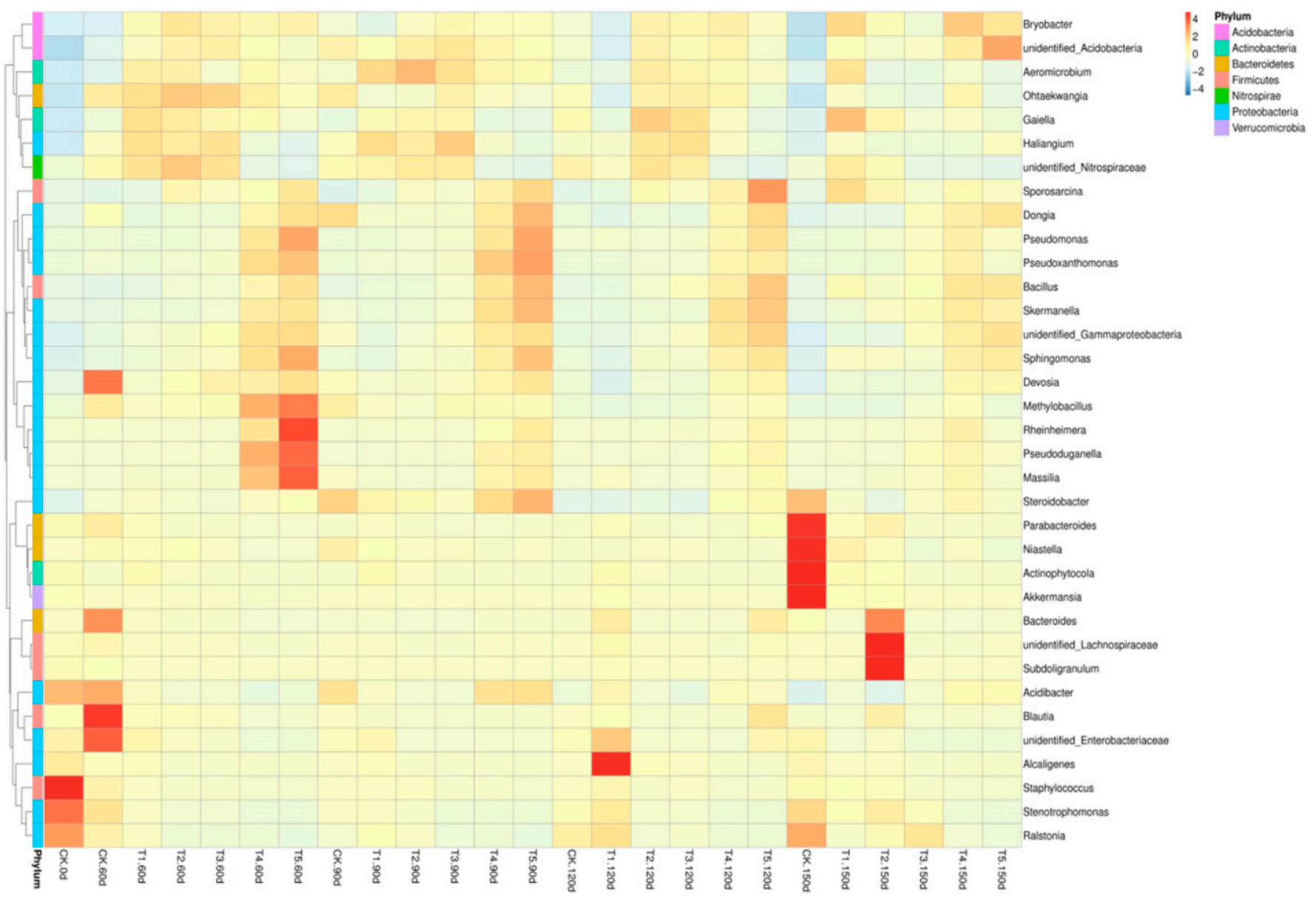

Fig. 8. Taxonomic composition and relative abundance of the soil bacterial genera with different doses of the additional pruning material. CK (garden soil cultivation alone), T1 (cultivated garden soil: crushed grape prunings $=100: 1), \mathrm{T} 2$ (cultivated garden soil: crushed grape prunings $=50: 1), \mathrm{T} 3($ cultivated garden soil: crushed grape prunings $=30: 1), \mathrm{T} 4$ (cultivated garden soil: crushed grape prunings $=20: 1)$, T5 $($ cultivated garden soil: crushed grape prunings $=$ 10:1). $60 \mathrm{~d}, 90 \mathrm{~d}, 120 \mathrm{~d}$, and $150 \mathrm{~d}$ indicate days after treatments. The horizontal axis of the figure shows sample information, and the vertical label shows genus information. A species cluster tree is shown at the left side of the figure. 

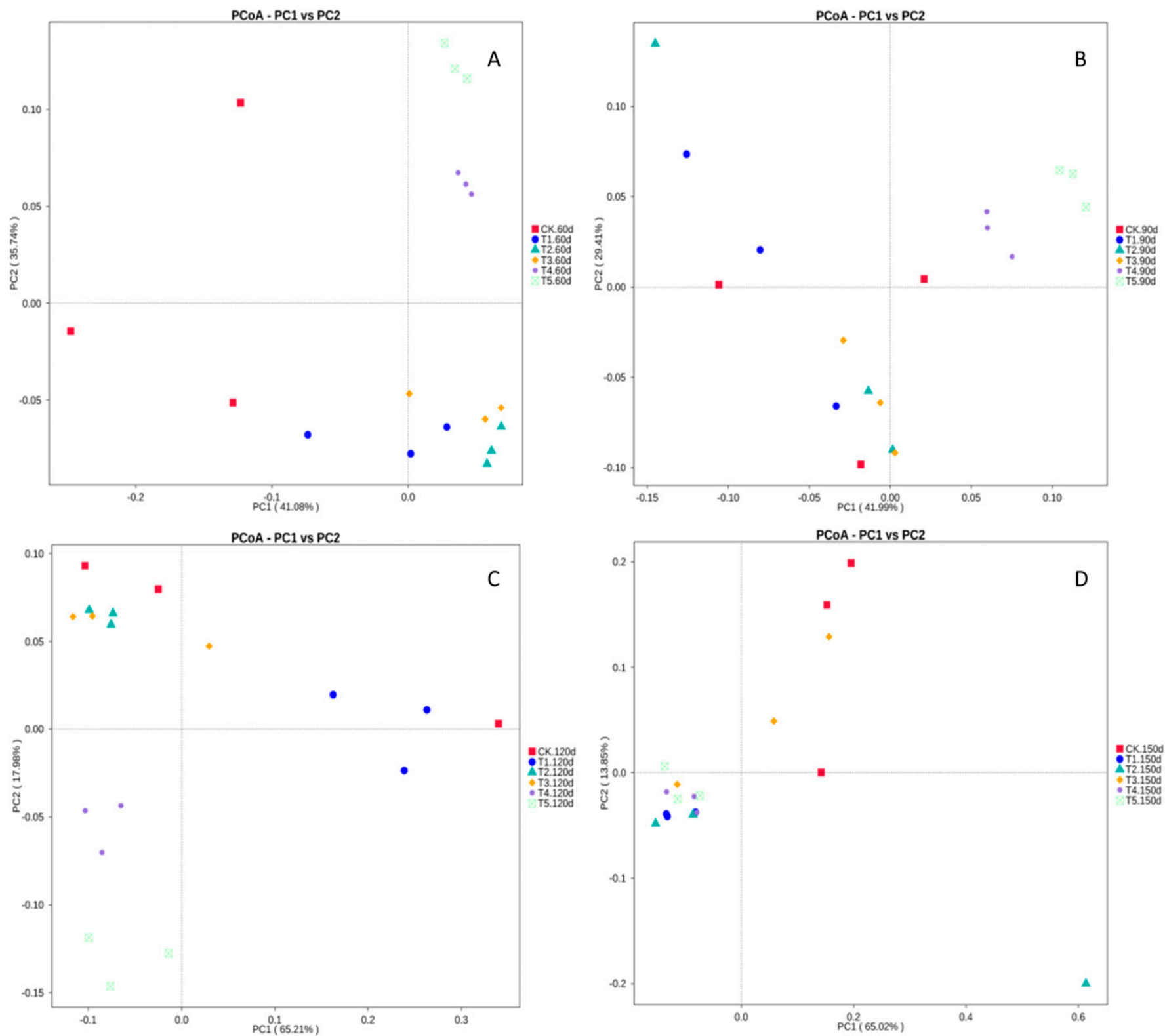

Fig. 9. Principal coordinates analysis of the soil bacterial community with different doses of the additional pruning material. CK (garden soil cultivation alone), T1 (cultivated garden soil: crushed grape prunings $=100: 1), \mathrm{T} 2$ (cultivated garden soil: crushed grape prunings $=50: 1$ ), T3 (cultivated garden soil: crushed grape prunings $=30: 1$ ), T4 (cultivated garden soil: crushed grape prunings $=20: 1$ ), T5 (cultivated garden soil: crushed grape prunings $=10: 1) .60 \mathrm{~d}, 90 \mathrm{~d}, 120 \mathrm{~d}$, and $150 \mathrm{~d}$ indicate days after treatments.

This indicated that in addition to the amounts of carbon source inputs, the enzyme activities may also be affected by the composition and degree of decomposition from the added source of the carbon (Zhao et al., 2019).

Different grape pruning supplements resulted in different soil bacterial community structures. The number and types of soil microorganisms have an irreplaceable role in the stability and diversity of soil ecosystems (Tiquia et al., 2002). At present, highthroughput sequencing technologies have been widely used for the analysis of soil microbial community structures and functional diversity. In this study, the NovaSeq6000 platform was used for high-throughput sequencing of the 16S rRNA gene V4 region of the soil bacteria in the grape root zone after the addition of the grape pruning material. When combined with bioinformatic analyses, it was found that the diversity and abundance of the soil bacterial communities in the grape root zone without the additional pruning material showed a trend of increasing first and then decreasing, reflecting the process of the native carbon substrate being used by the soil microorganisms. Different dosages of the grape pruning material increased the Shannon, ACE, and Chao 1 indices after $60 \mathrm{~d}$, of which the T2 and T3 treatments reached a significant level compared with the CK. The addition of the grape pruning material had little effect on the diversity and richness of the soil bacterial communities after 90 and $120 \mathrm{~d}$, but it increased the diversity and richness of the soil bacterial communities after $150 \mathrm{~d}$. Among them, the T1, T4, and T5 showed significant differences compared with the CK. This may be related to the addition of the exogenous pruning material, which provides more available carbon sources for the soil microorganisms that in turn promote the soil bacterial growth and reproduction. Zhao et al. (2019) also found that the soil bacterial diversity and richness indices improved after the addition of straw.

Species annotation analysis results showed that Proteobacteria, Acidobacteria, and Actinobacteria were the main bacterial groups in the soil of the grape root zone, which is similar to the predominant bacterial groups obtained in the different types of farmland soil; however, the relative abundances of each predominant group varied greatly in 
A

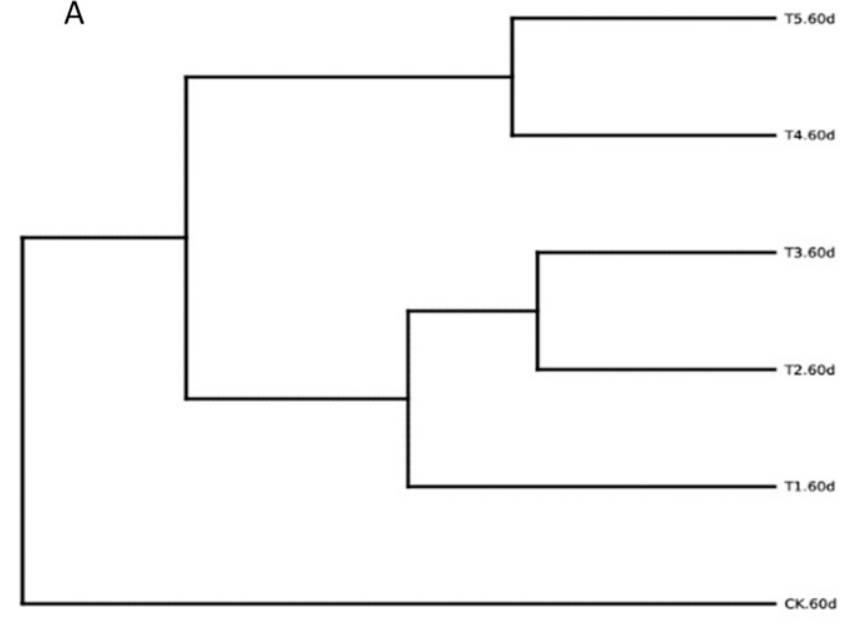

0.01

C

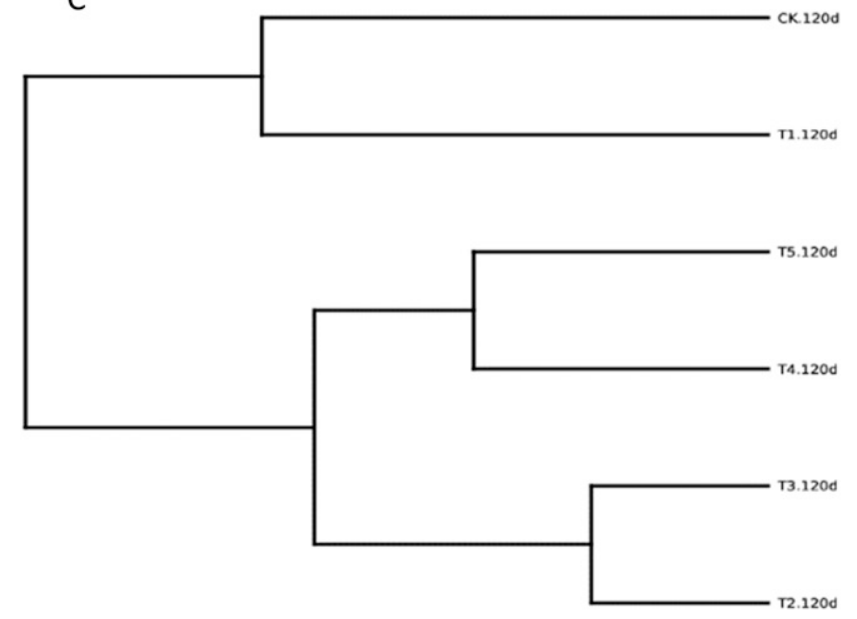

B

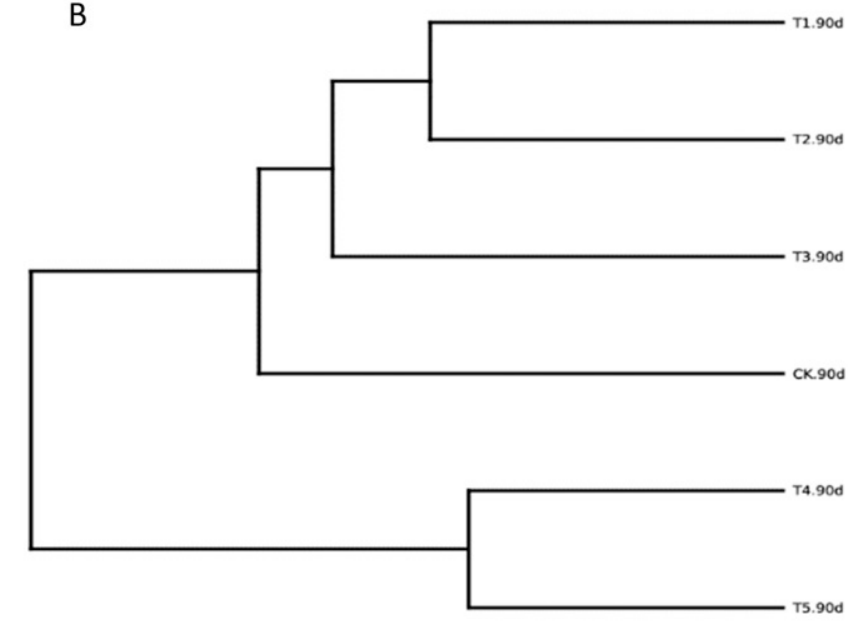

0.01

D

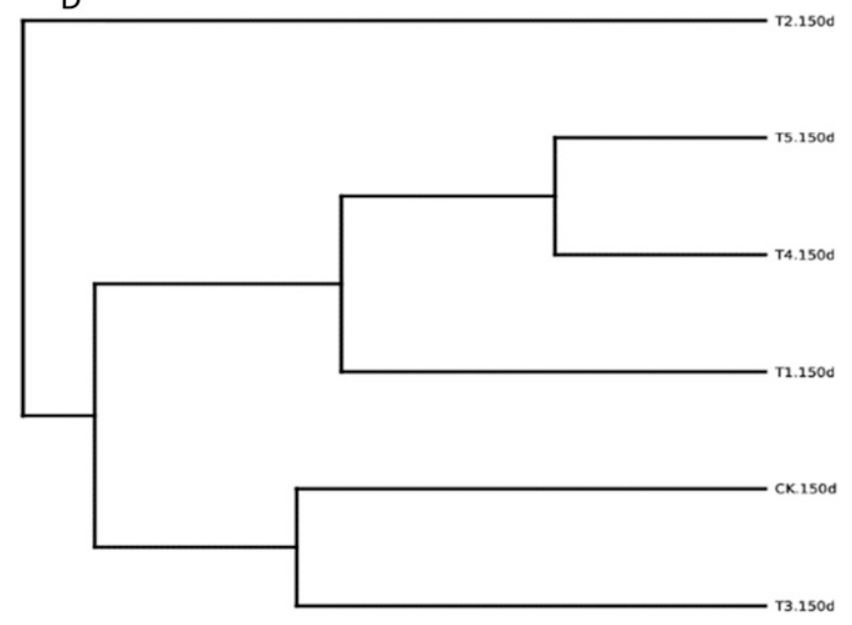

$\underline{0.01}$

Fig. 10. Unweighted pair-group method with arithmetic means (UPGMA) cluster analysis of the soil bacterial community with different doses of the additional pruning material. CK (garden soil cultivation alone), T1 (cultivated garden soil: crushed grape prunings = 100:1), T2 (cultivated garden soil: crushed grape prunings $=50: 1$ ), T3 (cultivated garden soil: crushed grape prunings $=30: 1)$, T4 (cultivated garden soil: crushed grape prunings $=20: 1)$, T5 $($ cultivated garden soil: crushed grape prunings $=10: 1) .60 \mathrm{~d}, 90 \mathrm{~d}, 120 \mathrm{~d}$, and $150 \mathrm{~d}$ indicate days after treatments.

the different studies. This is because the relative abundances of the dominant group were affected by soil type, soil texture, and crop varieties (Chu et al., 2010; Liu et al., 2014). In this study, the addition of the grape pruning material changed the relative abundances of the main phylum of the soil bacteria. Compared with the soil without the pruning material, the relative abundances of the soil bacterial phylum after treatments with the different dosages of the pruning material, showed the same trends after 60 and $150 \mathrm{~d}$, as both reduced the Proteobacteria and increased the Actinobacteria, Acidobacteria, Planctomycetes, and Chloroflexi. The T2-T5 treatments increased the relative abundance of Actinobacteria throughout the experiment. Among them, the highest relative abundances of Actinobacteria were found with the T2 treatment. Previous studies have suggested that Actinobacteria are eutrophic bacteria (Fierer et al., 2012; Zeng et al., 2016), that function to degrade hydrocarbons and play an important role in the process of plant decomposition and the nitrogen cycle (Lauber et al., 2008; Vesela et al., 2010). Fan et al. (2014) and Shrestha et al. (2011) found that Actinobacteria are an important bacterial population that degrades corn and rice straw. In this study, the relative abundances of Actinobacteria were relatively high, indicating that it played a key role in the degradation of the grape pruning material. Acidobacteria is another important group of soil bacterium. It makes up high proportion of the bacteria in most soils, plays an important role in soil nutrient cycling and microecological balances, and is an important carbon converter in soils (Fan et al., 2014). Studies have indicated that Acidobacteria has a cellulose-degrading function and plays an important role in the degradation of plant residues (Eichorst et al., 2011; Kanokratana et al., 2011; Pankratov et al., 2011, 2012). In this investigation, this may be because the addition of the pruning material increased the cellulose content to be degraded by the microorganisms, which in turn stimulated an increased abundance of Acidobacteria. In addition, Acidobacteria have a significant negative correlation with soil $\mathrm{pH}$ (Griffiths et al., 2011). In this experiment, the additional pruning material might have increased the proportion of aerobic bacteria in the soil by enhancing the permeability of the soil, as well as the decomposition of the nutrients by aerobic bacteria reduced the $\mathrm{pH}$ of the soil. This may be one reason why the abundance of Acidobacteria increased with the addition of the grape pruning material. Shrestha et al. (2011) pointed out that Chloroflexi is an important bacterial population that degrades rice straw. Our findings produced similar results, as the relative abundance of the Chloroflexi was higher both 60 and $150 \mathrm{~d}$ after the addition of the pruning material. 
Anaerolineae (a class of the Chloroflexi) could degrade carbohydrates, and genomic comparison analysis revealed that Anaerolineae SB1031 could conduct several of the glycolytic pathways, including cellulose hydrolysis (Xia et al., 2016). The results of this study indicated that Chloroflexi plays a role in the degradation of grape pruning materials, which might be related to the involvement of Chloroflexi in the cellulose hydrolysis of the pruning materials. Bacillus plays an important role in plant biotic and abiotic stress. It can induce several biomolecular changes that trigger plant growth and prevent pathogen infection (Radhakrishnan et al., 2017). In this study, the T2 treatment increased the relative abundance of Bacillus, which helps improve the stress resistance of the grape plants and is extremely beneficial to grape production.

In addition, some studies have pointed out that soil microorganisms are closely related to soil enzymes, and the factors affecting soil microorganisms also affect soil enzyme activities (Wang et al., 2019). This study found that with the increase of soil invertase, amylase, and $\beta$-glucosidase activity after the T2 treatment, the soil bacterial diversity and community abundances also increased.

\section{Conclusion}

Fresh weights were higher in the treatments with the lower pruning material content than in those with higher levels. Among them, compared with the CK, the T2 treatment significantly promoted root development. In contrast, the higher doses of the grape pruning material resulted in significant inhibition of plant biomass increases and root development. The T2 and T3 treatments significantly increased the SOC content, MBC content, and part of the soil enzyme activity, throughout the experiment. Adding the pruning material increased the diversity and richness of the soil bacterial communities after 60 and $150 \mathrm{~d}$. In production systems, the grape pruning material could be added to improve the soil microecology and promote the development of grape plants. For this, we recommend using a growing medium of evenly mixed cultivated garden soil and crushed grape prunings at a mass ratio of 50:1.

Follow-up research will carry out longterm positioning and continuous observations in field conditions. Furthermore, the correlation between the characteristics of the microbial community and the changes in the soil chemical properties and enzyme activities will be analyzed to further reveal the influences of soil microorganisms.

\section{Literature Cited}

Aslantas, R., R. Cakmakci, and F. Sahin. 2007. Effect of plant growth promoting rhizobacteria on young apple tree growth and fruit yield under orchard conditions. Scientia Hort. 111:371-377, doi: 10.1016/j.scienta.2006.12.016.

Badiane, N.N.Y., J.L. Chotte, E. Pate, D. Masse, and C. Rouland. 2001. Use of soil enzyme activities to monitor soil quality in natural and improved fallows in semi-arid tropical regions.
Appl. Soil Ecol. 18:229-238, doi: 10.1016/ S0929-1393(01)00159-7.

Bhattacharya, S.S., K.H. Kim, S. Das, M. Uchimiya, B.H. Jeon, E. Kwon, and J.E. Szulejko. 2016. A review on the role of organic inputs in maintaining the soil carbon pool of the terrestrial ecosystem. J. Environ. Mgt. 167:214-227, doi: 10.1016/j.jenvman.2015.09.042.

Brunel, C., R. Gros, T.Z. Lerch, and A.M.F.D. Silva. 2020. Changes in soil organic matter and microbial communities after fine and coarse residues inputs from Mediterranean tree species. Appl. Soil Ecol. 149:103516, doi: 10.1016/j.apsoil.2020.103516.

Burns, R.G., J.L. Deforest, J. Marxsen, R.L. Sinsabaugh, M.E. Stromberger, M.D. Wallenstein, M.N. Weintraub, and A. Zoppini. 2013. Soil enzymes in a changing environment: Current knowledge and future directions. Soil Biol. Biochem. 58:216-234, doi: 10.1016/j.soilbio. 2012.11.009.

Caporaso, J.G., J. Kuczynski, J. Stombaugh, K. Bittinger, F.D. Bushman, E.K. Costello, N. Fierer, A.G. Pena, J.K. Goodrich, J.I. Gordon, G.A. Huttley, S.T. Kelley, D. Knights, J.E. Koenig, R.E. Ley, C.A. Lozupone, D. Mcdonald, B.D. Muegge, M. Pirrung, J. Reeder, J.R. Sevinsky, P.J. Turnbaugh, W.A. Walters, J. Widmann, T. Yatsunenko, J. Zaneveld, and R. Knight. 2010. QIIME allows analysis of highthroughput community sequencing data. Nat. Methods 7:335-336, doi: 10.1038/nmeth.f.303.

Chan, K.Y., D.J. Fahey, M. Newell, and I. Barchia. 2010. Using composted mulch in vineyards-Effects on grape yield and quality. Intl. J. Fruit Sci. 10:441453, doi: 10.1080/15538362.2010.530135.

Chapin, F.S. 1980. The mineral nutrition of wild plants. Annu. Rev. Ecol. Syst. 11:233-260, doi: 10.1146/annurev.es.11.110180.001313.

Chu, H.Y., N. Fierer, C.L. Lauber, J.G. Caporaso, R. Knight, and P. Grogan. 2010. Soil bacterial diversity in the Arctic is not fundamentally different from that found in other biomes. Environ. Microbiol. 12:2998-3006, doi: 10.1111/ j.1462-2920.2010.02277.x.

Edgar, R.C. 2013. UPARSE: Highly accurate OTU sequences from microbial amplicon reads. Nat. Methods 10:996-998, doi: 10.1038/nmeth.2604.

Eichorst, S.A., C.R. Kuske, and T.M. Schmidt. 2011. Influence of plant polymers on the distribution and cultivation of bacteria in the phylum Acidobacteria. Appl. Environ. Microbiol. 77:586-596, doi: 10.1128/AEM.01080-10.

Emmerling, C., M. Schloter, A. Hartmann, and E. Kandeler. 2002. Functional diversity of soil organisms - A review of recent research activities in Germany. J. Plant Nutr. Soil Sci. 165:408-420, doi: 10.1002/1522-2624(200208)165:4<408:AIDJPLN408>3.0.CO;2-3.

Fan, F., C. Yin, Y.J. Tang, Z.J. Li, A. Song, S.A. Wakelin, J. Zou, and Y.C. Liang. 2014. Probing potential microbial coupling of carbon and nitrogen cycling during decomposition of maize residue by ${ }^{13} \mathrm{C}$-DNA-SIP. Soil Biol. Biochem. 70:12-21, doi: 10.1016/j.soilbio. 2013.12.002.

Fan, T.L., B.A. Stewart, W. Yong, J.J. Luo, and G.Y. Zhou. 2005. Long-term fertilization effects on grain yield, water-use efficiency and soil fertility in the dryland of Loess Plateau in China. Agr. Ecosyst. Environ. 106:313-329, doi: 10.1016/j.agee.2004.09.003.

Fierer, N., C.L. Lauber, K.S. Ramirez, J. Zaneveld, M.A. Bradford, and R. Knight. 2012. Comparative metagenomic, phylogenetic and physiological analyses of soil microbial communities across nitrogen gradients. ISME J. 6:10071017, doi: 10.1038/ismej.2011.159.
Gaiotti, F., P. Marcuzzo, N. Belfiore, L. Lovat, F. Fornasier, and D. Tomasi. 2017. Influence of compost addition on soil properties, root growth and vine performances of Vitis vinifera cv Cabernet sauvignon. Scientia Hort. 225:8895, doi: 10.1016/j.scienta.2017.06.052.

Griffiths, R.I., B.C. Thomson, P. James, T. Bell, M.J. Bailey, and A.S. Whiteley. 2011. The bacterial biogeography of British soils. Environ. Microbiol. 13:1642-1654, doi: 10.1111/ j.1462-2920.2011.02480.x.

Guo, L.J., Z.S. Zhang, D.D. Wang, C.F. Li, and C.G. Cao. 2015. Effects of short-term conservation management practices on soil organic carbon fractions and microbial community composition under a rice-wheat rotation system. Biol. Fertil. Soils 51:65-75, doi: 10.1007/ s00374-014-0951-6.

Hodge, A. 2006. Plastic plants and patchy soils. J. Expt. Bot. 57:401-411, doi: $10.1093 / \mathrm{jxb} /$ eri280.

Hojjati, S. and F. Nourbakhsh. 2007. Effects of cow manure and sewage sludge on the activity and kinetics of L-glutaminase in soil. Biol. Fertil. Soils 43:491-494, doi: 10.1007/s00374-0060149-7.

Huang, Z., Z. Xu, and C. Chen. 2008. Effect of mulching on labile soil organic matter pools, microbial community functional diversity and nitrogen transformations in two hardwood plantations of subtropical Australia. Appl. Soil Ecol. 40:229-239, doi: 10.1016/j.apsoil.2008.04.009.

Jia, Z.J., Y. Kuzyakov, D. Myrold, and J.M. Tiedje. 2017. Soil organic carbon in a changing world. Pedosphere 27:789-791, doi: 10.1016/S10020160(17)60489-2.

Jiang, G.Y., H. Zhang, Y.J. Zhang, J.F. Zhu, S.L. Liu, and F. Liu. 2017. The response of the agronomical traits and chemical components of tobacco to organic materials with varied carbon/ nitrogen ratios. Agr. Res. Arid Areas 35:61-67, doi: 10.7606/j.issn.1000-7601.2017.04.10.

Jin, Y., D.A. Ni, and Y.L. Ruan. 2009. Posttranslational elevation of cell wall invertase activity by silencing its inhibitor in tomato delays leaf senescence and increases seed weight and fruit hexose level. Plant Cell 21:2072-2089, doi: $10.1105 /$ tpc. 108.063719 .

Kanokratana, P., T. Uengwetwanit, U. Rattanachomsri, B. Bunterngsook, T. Nimchua, S. Tangphatsornruang, V. Plengvidhya, V. Champreda, and L. Eurwilaichitr. 2011. Insights into the phylogeny and metabolic potential of a primary tropical peat swamp forest microbial community by metagenomic analysis. Microb. Ecol. 61:518-528, doi: 10.1007/s00248-0109766-7.

Kjallstrand, J., O. Ramnas, and G. Petersson. 1998. Gas chromatographic and mass spectrometric analysis of 36 lignin-related methoxyphenols from uncontrolled combustion of wood. J. Chromatography 824:205-210, doi: 10.1016/ S0021-9673(98)00698-0.

Lauber, C.L., M.S. Strickland, M.A. Bradford, and N. Fierer. 2008. The influence of soil properties on the structure of bacterial and fungal communities across land-use types. Soil Biol. Biochem. 40:2407-2415, doi: 10.1016/j.soilbio.2008.05.021.

Lazcano, C., J. Arnold, A. Tato, J.G. Zaller, and J. Dominguez. 2009. Compost and vermicompost as nursery pot components: Effects on tomato plant growth and morphology. Span. J. Agr. Res. 7:944-951, doi: 10.5424/sjar/20090741107.

Li, C.L., J.B. Xu, Y.Q. He, Y.L. Liu, and J.B. Fan. 2012. Dynamic relationship between biologically active soil organic carbon and aggregate stability in long-term organically fertilized 
soils. Pedosphere 22:616-622, doi: 10.1016/ S1002-0160(12)60046-0.

Liu, J.J., Y.Y. Sui, Z.H. Yu, Y. Shi, H.Y. Chu, J. Jin, X.B. Liu, and G.H. Wang. 2014. High throughput sequencing analysis of biogeographical distribution of bacterial communities in the black soils of northeast China. Soil Biol. Biochem. 70:113-122, doi: 10.1016/j.soilbio.2013.12.014.

Liu, Z., T.P. Gao, W.T. Liu, K. Sun, Y.N. Xin, H.J. Liu, S.Z. Wang, G. Li, H.F. Han, Z.J. Li, and T.Y. Ning. 2019. Effects of part and whole straw returning on soil carbon sequestration in C3-C4 rotation cropland. J. Plant Nutr. Soil Sci. 182:429-440, doi: 10.1002/jpln.201800573.

Lynch, J.P. and K.M. Brown. 2012. New roots for agriculture: Exploiting the root phenome. Philosophical Trans. Royal Soc. B 367:1598-1604, doi: $10.1098 /$ rstb.2011.0243.

Lyu, S.S. 2017. The study of returning apple branches degradation and their effect on soil and the respiratory metabolism of root-stock. PhD Diss, Shenyang Agricultural Univ., China. (In Chinese).

Mbuthia, L.W., V. Acostamartinez, J.M. Debruyn, S.M. Schaeffer, D.D. Tyler, E.W. Odoi, M. Mpheshea, F. Walker, and N.S. Eash. 2015. Long term tillage, cover crop, and fertilization effects on microbial community structure, activity: Implications for soil quality. Soil Biol. Biochem. 89:24-34, doi: 10.1016/j.soilbio.2015. 06.016.

Mininni, C., M.A. Bustamante, E. Medina, F.F. Montesano, C. Paredes, A. Perezespinosa, R. Moral, and P. Santamaria. 2013. Evaluation of posidonia seaweed-based compost as a substrate for melon and tomato seedling production. J. Hort. Sci. Biotechnol. 88:345-351, doi: 10.1080/14620316.2013.11512975.

Mininni, C., P. Santamaria, H. Abdelrahman, C. Cocozza, T.M. Miano, F.F. Montesano, and A. Parente. 2012. Posidonia-based compost as a peat substitute for lettuce transplant production. HortScience 47:1438-1444, doi: 10.21273/ hortsci.47.10.1438.

Montanaro, G., B. Dichio, C.B. Bati, and C. Xiloyannis. 2012. Soil management affects carbon dynamics and yield in a Mediterranean peach orchard. Agr. Ecosyst. Environ. 161:4654, doi: 10.1016/j.agee.2012.07.020.

Moralescorts, M.R., M.A. Gomezsanchez, and R. Perezsanchez. 2014. Evaluation of green/pruning wastes compost and vermicompost, slumgum compost and their mixes as growing media for horticultural production. Scientia Hort. 172:155160, doi: 10.1016/j.scienta.2014.03.048.

Ng, E.L., A.F. Patti, M.T. Rose, C.R. Schefe, K. Wilkinson, R.J. Smernik, and T.R. Cavagnaro. 2014. Does the chemical nature of soil carbon drive the structure and functioning of soil microbial communities. Soil Biol. Biochem. 70:54-61, doi: 10.1016/j.soilbio.2013.12.004.

Nsabimana, D., R.J. Haynes, and F.M. Wallis. 2004. Size, activity and catabolic diversity of the soil microbial biomass as affected by land use. Appl. Soil Ecol. 26:81-92, doi: 10.1016/ j.apsoil.2003.12.005.

Pankratov, T.A., A.O. Ivanova, S.N. Dedysh, and W. Liesack. 2011. Bacterial populations and environmental factors controlling cellulose degradation in an acidic Sphagnum peat. Environ. Microbiol. 13:1800-1814, doi: 10.1111/ j.1462-2920.2011.02491.x.

Pankratov, T.A., L.A. Kirsanova, E.N. Kaparullina, V.V. Kevbrin, and S.N. Dedysh. 2012. Telmatobacter bradus gen. nov., sp. nov., a cellulolytic facultative anaerobe from subdivision 1 of the Acidobacteria, and emended description of
Acidobacterium capsulatum Kishimoto et al. 1991. Intl. J. Systematic Evolutionary Microbiology 62:430-437, doi: 10.1099/ijs.0.029629-0.

Perezlomas, A.L., G. Delgado, J. Parraga, R. Delgado, G. Almendros, and V. Aranda. 2010. Evolution of organic matter fractions after application of co-compost of sewage sludge with pruning waste to four Mediterranean agricultural soils. A soil microcosm experiment. Waste Mgt. 30:1957-1965, doi: 10.1016/j.wasman.2010.04.030.

Qiu, Q.Y., L.F. Wu, Z. Ouyang, B.B. Li, Y.Y. Xu, S.S. Wu, and E.G. Gregorich. 2016. Priming effect of maize residue and urea $\mathrm{N}$ on soil organic matter changes with time. Appl. Soil Ecol. 100:65-74, doi: 10.1016/j.apsoil.2015.11.016.

Radhakrishnan, R., A. Hashem, and E.F.A. Allah. 2017. Bacillus: A biological tool for crop improvement through bio-molecular changes in adverse environments. Front. Physiol. 8:667667, doi: 10.3389/fphys.2017.00667.

Ramos, M.E., E. Benitez, P.A. Garcia, and A.B. Robles. 2010. Cover crops under different managements vs. frequent tillage in almond orchards in semiarid conditions: Effects on soil quality. Appl. Soil Ecol. 44:6-14, doi: 10.1016/ j.apsoil.2009.08.005.

Reich, P.B., J. Oleksyn, J. Modrzynski, P. Mrozinski, S.E. Hobbie, D.M. Eissenstat, J. Chorover, O.A. Chadwick, C.M. Hale, and M.G. Tjoelker. 2005. Linking litter calcium, earthworms and soil properties: A common garden test with 14 tree species. Ecol. Lett. 8:811-818, doi: 10.1111/ j.1461-0248.2005.00779.x.

Schipper, L.A. and G.P. Sparling. 2011. Accumulation of soil organic $\mathrm{C}$ and change in $\mathrm{C}: \mathrm{N}$ ratio after establishment of pastures on reverted scrubland in New Zealand. Biogeochemistry 104:49-58, doi: 10.1007/s10533-009-9367-z.

Shao, J.G., Y.B. Li, C.F. Wei, and D.T. Xie. 2009. Effects of land management practices on labile organic carbon fractions in rice cultivation. Chin. Geogr. Sci. 19:241-248, doi: 10.1007/ s11769-009-0241-7.

Shrestha, M., P.M. Shrestha, and R. Conrad. 2011. Bacterial and archaeal communities involved in the in situ degradation of ${ }^{13} \mathrm{C}$-labelled straw in the rice rhizosphere. Environ. Microbiol. Rpt. 3:587-596, doi: 10.1111/j.1758-2229.2011.00267.x.

Singh, G., S.K. Jalota, and Y. Singh. 2007. Manuring and residue management effects on physical properties of a soil under the rice-wheat system in Punjab, India. Soil Tillage Res. 94:229-238, doi: 10.1016/j.still.2006.07.020.

Sparling, G.P. 1992. Ratio of microbial biomass carbon to soil organic carbon as a sensitive indicator of changes in soil organic matter. Soil Res. 30:195-207, doi: 10.1071/sr9920195.

Springob, G. and H. Kirchmann. 2003. Bulk soil C to $\mathrm{N}$ ratio as a simple measure of net $\mathrm{N}$ mineralization from stabilized soil organic matter in sandy arable soils. Soil Biol. Biochem. 35:629-632, doi: 10.1016/S0038-0717(03)00052$\mathrm{X}$.

Teutscherova, N., E. Vazquez, D. Santana, M. Navas, A. Masaguer, and M. Benito. 2017. Influence of pruning waste compost maturity and biochar on carbon dynamics in acid soil: Incubation study. Eur. J. Soil Biol. 78:66-74, doi: 10.1016/j.ejsobi.2016.12.001.

Tiquia, S.M., J. Lloyd, D.A. Herms, H.A.J. Hoitink, and F.C. Michel. 2002. Effects of mulching and fertilization on soil nutrients, microbial activity and rhizosphere bacterial community structure determined by analysis of TRFLPs of PCR-amplified 16S rRNA genes. Appl. Soil Ecol. 21:31-48, doi: 10.1016/S0929-1393(02) 00040-9.
Torres, I.F., F. Bastida, T. Hernandez, and C. Garcia. 2015. The effects of fresh and stabilized pruning wastes on the biomass, structure and activity of the soil microbial community in a semiarid climate. Appl. Soil Ecol. 89:1-9, doi: 10.1016/j.apsoil.2014.12.009.

Torres, I.F., F. Bastida, T. Hernandez, P. Bombach, H.H. Richnow, and C. Garcia. 2014. The role of lignin and cellulose in the carbon-cycling of degraded soils under semiarid climate and their relation to microbial biomass. Soil Biol. Biochem. 75:152-160, doi: 10.1016/j.soilbio.2014.04.007.

Uselman, S.M., R.G. Qualls, and J. Lilienfein. 2012. Quality of soluble organic C, N, and P produced by different types and species of litter: Root litter versus leaf litter. Soil Biol. Biochem. 54:57-67, doi: 10.1016/j.soilbio. 2012.03.021.

Vance, E.D., P.C. Brookes, and D.S. Jenkinson. 1987. An extraction method for measuring soil microbial biomass C. Soil Biol. Biochem. 19:703-707, doi: 10.1016/0038-0717(87) 90052-6

Veen, J.A.V., J.N. Ladd, and M. Amato. 1985. Turnover of carbon and nitrogen through the microbial biomass in a sandy loam and a clay soil incubated with $\left[{ }^{14} \mathrm{C}(\mathrm{U})\right]$ glucose and $\left[{ }^{15} \mathrm{~N}\right]\left(\mathrm{NH}_{4}\right)_{2} \mathrm{SO}_{4}$ under different moisture regimes. Soil Biol. Biochem. 17:747-756, doi: 10.1016/0038-0717(85)90128-2.

Vesela, A.B., M. Franc, H. Pelantova, D. Kubac, V. Vejvoda, M. Sulc, T.C. Bhalla, M. Mackova, P. Lovecka, P. Janu, K. Demnerova, and L. Martinkova. 2010. Hydrolysis of benzonitrile herbicides by soil actinobacteria and metabolite toxicity. Biodegradation 21:761-770, doi: 10.1007/s10532-010-9341-4.

Waldrop, M.P. and M.K. Firestone. 2004. Microbial community utilization of recalcitrant and simple carbon compounds: Impact of oakwoodland plant communities. Oecologia 138: 275-284, doi: 10.1007/s00442-003-1419-9.

Wang, C., G. Li, S.J. Huang, C. Zhang, W. Tian, R. Tian, L. Wang, and Y.G. Xi. 2019. Effect of Bacillus subtilis microbial fertilizer on root-zone soil microbial ecology of organic Chinese watermelon, Microbiol. China 46 563-576, (In Chinese), doi: 10.13344/j.microbiol.china. 180165 .

Wang, Q., G.M. Garrity, J.M. Tiedje, and J.R. Cole. 2007. Naive Bayesian classifier for rapid assignment of rRNA sequences into the new bacterial taxonomy. Appl. Environ. Microbiol. 73:5261-5267, doi: 10.1128/AEM.00062-07.

Xi, X.H., Z.F. Yang, Y.J. Cui, S.M. Sun, C.G. Yu, and M. Li. 2011. A study of soil organic carbon distribution and storage in the Northeast Plain of China. Geoscience Frontiers 2:115-123, doi: 10.1016/j.gsf.2011.02.001.

Xia, Y., Y.B. Wang, Y. Wang, F.Y.L. Chin, and T. Zhang. 2016. Cellular adhesiveness and cellulolytic capacity in Anaerolineae revealed by omics-based genome interpretation. Biotechnol. Biofuels 9:111, doi: 10.1186/s13068-0160524-Z.

Xu, X.F., C.C. Song, X. Song, and X.S. Song. 2004. Carbon mineralization and the related enzyme activity of soil in wetland. Ecol. Environ. 13: 40-42. (In Chinese), doi: 10.16258/j.cnki.16745906.2004.01.021

Yang, X., J. Meng, Y. Lan, W.F. Chen, T.X. Yang, J. Yuan, S.N. Liu, and J. Han. 2017. Effects of maize stover and its biochar on soil $\mathrm{CO}_{2}$ emissions and labile organic carbon fractions in northeast China. Agr. Ecosyst. Environ. 240:24-31, doi: 10.1016/j.agee.2017.02.001. 
Young, I.M. and J.W. Crawford. 2004. Interactions and self-organization in the soil-microbe complex. Science 304:1634-1637, doi: 10.1126/ science.1097394.

Yu, C.Y., H. Liu, Y.D. Xing, N.S. Manukovsky, V.S. Kovalev, and Y.L. Gurevich. 2008. Bioconversion of rice straw into a soil-like substrate. Acta Astronaut. 63:1037-1042, doi: 10.1016/j.actaastro.2008.03.010.
Zeng, J., X.J. Liu, L. Song, X.G. Lin, H.Y. Zhang, C.C. Shen, and H.Y. Chu. 2016. Nitrogen fertilization directly affects soil bacterial diversity and indirectly affects bacterial community composition. Soil Biol. Biochem. 92:4149, doi: 10.1016/j.soilbio.2015.09.018.

Zhao, H.L., Y.H. Jiang, P. Ning, J.F. Liu, W. Zheng, X.H. Tian, J.L. Shi, M. Xu, Z.Y. Liang, and A.G. Shar. 2019. Effect of different straw return modes on soil bacterial community, enzyme activities and organic carbon fractions. Soil Sci. Soc. Amer. J. 83:638-648, doi: 10.2136/sssaj2018.03.0101.

Zhao, S.C., K.J. Li, W. Zhou, S.J. Qiu, S.W. Huang, and P. He. 2016. Changes in soil microbial community, enzyme activities and organic matter fractions under long-term straw return in north-central China. Agr. Ecosyst. Environ. 216:82-88, doi: 10.1016/j.agee.2015.09.028. 
48 seedlings for each treatment

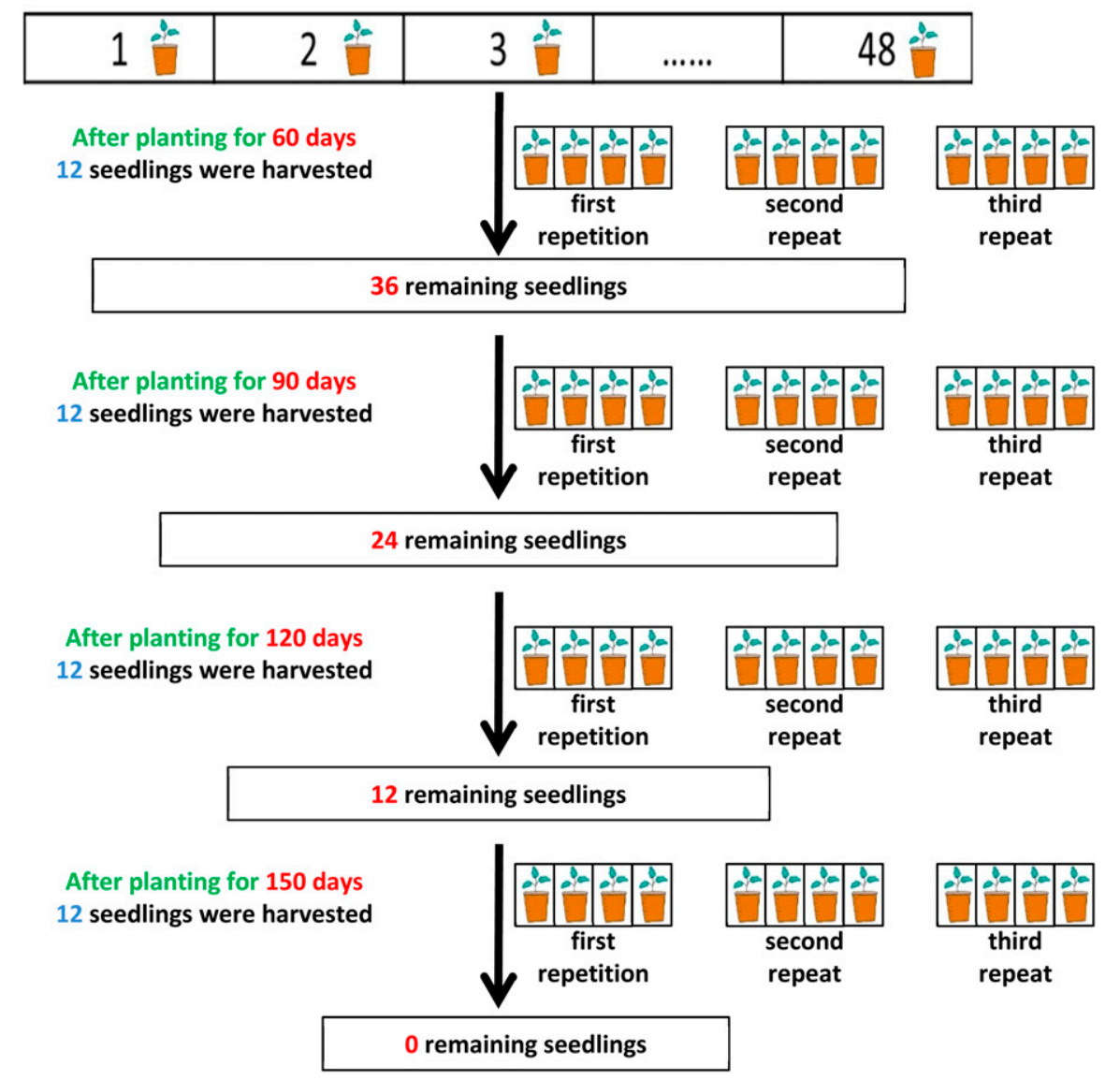

Supplemental Fig. 1. Sampling period and method for each treatment. 